Article

\title{
Formulation and Characterization of Antimicrobial Edible Films Based on Whey Protein Isolate and Tarragon Essential Oil
}

\author{
Maria-Ioana Socaciu ${ }^{1}$ (D), Melinda Fogarasi ${ }^{2}$ (D) Cristina Anamaria Semeniuc 2,*iD, \\ Sonia Ancuţa Socaci ${ }^{1}$ (D), Mihaela Ancuţa Rotar ${ }^{1}$ (D), Vlad Mureşan ${ }^{2} \mathbb{D}$, Oana Lelia Pop ${ }^{1}$ and \\ Dan Cristian Vodnar $1, *$ (D) \\ 1 Department of Food Science, University of Agricultural Sciences and Veterinary Medicine Cluj-Napoca, \\ 3-5 Mănăştur St., 400372 Cluj-Napoca, Romania; maria-ioana.socaciu@usamvcluj.ro (M.-I.S.); \\ sonia.socaci@usamvcluj.ro (S.A.S.); anca.rotar@usamvcluj.ro (M.A.R.); oana.pop@usamvcluj.ro (O.L.P.) \\ 2 Department of Food Engineering, University of Agricultural Sciences and Veterinary Medicine Cluj-Napoca, \\ 3-5 Mănăştur St., 400372 Cluj-Napoca, Romania; melinda.fogarasi@usamvcluj.ro (M.F.); \\ vlad.muresan@usamvcluj.ro (V.M.) \\ * Correspondence: cristina.semeniuc@usamvcluj.ro (C.A.S.); dan.vodnar@usamvcluj.ro (D.C.V.); \\ Tel.: +40-264-596-384 (C.A.S. \& D.C.V.)
}

Received: 14 July 2020; Accepted: 3 August 2020; Published: 5 August 2020

\begin{abstract}
The effects of heat treatment and the addition of tarragon essential oil on physical and mechanical properties of films prepared with 5\% whey protein isolate (WPI) and 5\% glycerol were investigated in this study. Heat treatment of the film-forming solution caused increases in thickness, moisture content, swelling degree, water vapor permeability (WVP), $b^{*}$-value, $\Delta E^{*}$-value, transmittance values in the 200-300-nm region, transparency, and puncture resistance of the film, but decreases in water solubility, $L^{*}$-value, $a^{*}$-value, transmittance values in the 350-800-nm region, and puncture deformation. When incorporated with tarragon essential oil, heat-treated films have the potential to be used as antimicrobial food packaging. The addition of tarragon essential oil in film-forming solution caused increases in moisture content, solubility in water, WVP, $a^{*}$-value, $b^{*}$-value, $\Delta E^{*}$-value, and transparency of the film; decreases in transmittance values in the range of 600-800 nm; and variations in swelling degree, $L^{*}$-value, transmittance values in the range of $300-550 \mathrm{~nm}$, puncture resistance, and puncture deformation. Nevertheless, different tendencies were noticed in UNT (untreated) and HT (heat-treated) films with regards to transparency, light transmittance, puncture resistance, and puncture deformation. Based on these findings, HT films show improved physical and mechanical properties and, therefore, are more suitable for food-packaging applications.
\end{abstract}

Keywords: edible films; whey protein isolate; tarragon essential oil; heat treatment; antimicrobial properties; physical properties; mechanical properties

\section{Introduction}

In recent years, research has focused on the development of edible films and coatings with antimicrobial activity to control microorganisms that can cause food spoilage or food poisoning [1]. Edible films and coatings have many advantages such as biodegradability, edibility, bio-compatibility, aesthetic appearance, ability to resist physical stress, and barrier properties (permeability to moisture, oxygen, aroma, and oil) [2,3].

Essential oils are among the active agents used to enhance the functionality of edible films. It is well known essential oils possess antioxidant, antibacterial, and antifungal properties and that their chemical compounds are responsible for these $[1,4,5]$. Several studies have reported that essential oil of tarragon 
exhibits antioxidant activity [6-9] and is efficient against various food-related microorganisms such as Bacillus subtilis [10], Escherichia coli [7,10], Pseudomonas aeruginosa [10], Staphylococcus aureus [7,8,10], Listeria monocytogenes [8], Proteus vulgaris [10], Alcaligenes faecalis [8], Shigella dysenteriae [8], Aerobacter aerogenes [10], Candida albicans [7,11], Saccharomyces cerevisiae var. chevalieri [11], and Aspergillus niger [6,7]. The essential oil content in the aerial part of tarragon plants ranges between 0.15 and $3.1 \%$. Major components of the essential oil of tarragon differ significantly depending on the origin of the material. Essential oils extracted from Russian tarragon have been reported to be terpinen-4-ol (up to $41.34 \%$ ), sabinene (up to $39 \%$ ), and elemicin (up to $57 \%$ ). In essential oils extracted from French tarragon, estragole (up to $74 \%$ ) was found to be the main compound [12].

Preparation of edible films and coatings are based on polysaccharide, protein, or lipid polymers [13]. Compared to polysaccharides and lipids, protein-based polymers are the most useful due to impressive gas barrier properties; the oxygen permeability of soy protein-based films is $260,500,540$, and 670 times lower than that of low-density methyl cellulose, polyethylene, starch, and pectin [14]. Whey proteins can produce films with excellent barrier properties to oxygen, aroma, and oil at low-to-intermediate relative humidity and also with adequate mechanical properties that provide them durability when used as coatings or films for packaging applications [14,15]. Whey protein isolate (WPI) is the whey protein product with the highest protein content, more than $90 \%$ water-soluble milk proteins [16]. It is produced from whey protein concentrate (WPC) through demineralization by ion exchange [15]. Native whey proteins do not exhibit good adhesive properties due to their low molecular weights and compact globular structures [17]. Heat denaturation above $65^{\circ} \mathrm{C}$ opens the $\beta$-lactoglobulin globular structure, exposes sulfhydryl and hydrophobic groups, and thus induces oxidation of free sulfhydryls, disulfide bond interchange, and hydrophobic bonding. These reactions result in the formation of water-insoluble edible films, with good adhesive properties $[17,18]$. The making of protein-based films generally requires the incorporation of a minimal content of plasticizer, $3 \%$, to reduce the brittleness $[19,20]$. The addition of a plasticizer in the denatured film solutions improves the flexibility of films but increases the water vapor permeability (WVP) [21]. The most commonly used plasticizer for the preparation of protein-based films is glycerol since it is miscible in most proteins [22].

In light of the preceding considerations, this work aimed to gather a set of data to support the comparative characterization of whey protein isolate (WPI)-based edible films obtained from untreated (UNT) and heat-treated (HT) film-forming solutions with different levels of incorporated tarragon essential oil $(0.5,1.0,1.5,2.0$, and $2.5 \%, w / w)$. The current study focused on (1) the characterization of tarragon essential oil by determination of its total phenolic content, volatile constituents, antioxidant capacity, and antibacterial activity against Staphylococcus aureus, Escherichia coli, Salmonella enteritidis, and Listeria monocytogenes, and (2) the characterization of films by determination of their thickness, moisture content, swelling degree, solubility in water, water vapor permeability (WVP), color, light transmittance, transparency, puncture resistance (PR), and puncture deformation (PD).

\section{Materials and Methods}

\subsection{Plant Material and Essential Oil Extraction}

For the extraction of essential oil, commercially available dried leaves of tarragon were purchased from a company that markets food ingredients (Solina Group, Alba Iulia, Romania, http://www.solinagroup.ro). The essential oil of tarragon was obtained by hydrodistillation using a Clevenger-type apparatus (S.C. Energo-Metr S.R.L., Odorheiu Secuiesc, Romania), $50 \mathrm{~g}$ of dried leaves being boiled for $3 \mathrm{~h}$ with $750 \mathrm{~mL}$ distilled water. The essential oil of tarragon was dried over anhydrous sodium sulphate and stored at $4{ }^{\circ} \mathrm{C}$ prior to analysis. The extraction yield was calculated as the volume of essential oil (mL) per dried leaves' weight (g) and multiplied by 100 [5]. 


\subsubsection{ITEX/GC-MS Analysis of Tarragon Essential Oil}

The qualitative ITEX/GC-MS (in-tube extraction coupled with gas chromatography-mass spectrometry) analysis of volatile constituents was carried out as described in our previous report [5]. A sample of $1 \mu \mathrm{L}$ volume was measured into a sealed-cap headspace vial $(20 \mathrm{~mL})$ and maintained on continuous agitation at $60^{\circ} \mathrm{C}$ for $10 \mathrm{~min}$. The adsorption ( 5 strokes) of volatile constituents from the gaseous phase of tarragon essential oil was performed by a Combi PAL AOC-5000 autosampler (CTC Analytics, Zwingen, Switzerland) with a headspace syringe ITEX-II equipped with a microtrap (ITEX-2TrapTXTA, Tenax TA 80/100 mesh, Switzerland). The analytes were released by thermal desorption into the injection port of the GC-MSQP2010 system (Shimadzu, Kyoto, Japan); the microtrap was then flash-heated with $\mathrm{N}_{2}$.

A Zebron ZB-5 ms capillary column $(30 \mathrm{~m} \times 0.25 \mathrm{~mm}$ i.d. $\times 0.25 \mu \mathrm{m}$ film thickness; Phenomenex, Torrance, CA, USA) was used for the chromatographic separation of volatile constituents. The column oven temperature program was set as follows: From $40^{\circ} \mathrm{C}$ (kept at this temperature for $2 \mathrm{~min}$ ) to $160^{\circ} \mathrm{C}$ at $4{ }^{\circ} \mathrm{C} / \mathrm{min}$, then raised to $240{ }^{\circ} \mathrm{C}$ at $15{ }^{\circ} \mathrm{C} / \mathrm{min}$ (kept at this temperature for $5 \mathrm{~min}$ ). The temperature of the ion source, injector, and interface was set at $250^{\circ} \mathrm{C}$. Helium was used as the carrier gas at a flow rate of $1 \mathrm{~mL} / \mathrm{min}$. The split ratio was 1:300. The ion trap mass spectrometer was operated in EI-MS mode; the acquisition mode was set in the range of 40-650 $\mathrm{m} / \mathrm{z}$.

The volatile compounds were tentatively identified by comparing their mass spectra with those in the NIST27 and NIST147 libraries (considering a minimum similarity of $85 \%$ ) and by retention indices obtained from www.pherobase.com [23] or www.flavornet.org (for columns with a similar stationary phase to ZB-5 ms) [24]. The results were expressed as the relative percentage of each compound from the total ion chromatograms (TIC) area (100\%).

\subsubsection{Determination of Total Phenolic Content}

The total phenolic content was measured using the method described by Semeniuc et al. (2018) [5]. One hundred microliters of the test sample (dilution of tarragon essential oil with methanol, 1:50 $(v / v)$ ) were transferred into a 16-mL glass bottle with a rubber stopper. Then, $6 \mathrm{~mL}$ of distilled water and $0.5 \mathrm{~mL}$ of $2 \mathrm{~N}$ Folin-Ciocalteu phenol reagent were added and immediately vortexed (Vortex V-1 Plus, Biosan Ltd., Riga, Latvia). After $4 \mathrm{~min}, 1.5 \mathrm{~mL}$ of $0.71 \mathrm{M}$ sodium carbonate aqueous solution and $1.9 \mathrm{~mL}$ of distilled water were added to the mixture. The incubation of the test sample was carried out in the dark at room temperature for $2 \mathrm{~h}$. The absorbance value was read at $725 \mathrm{~nm}$ against the blank sample using a double-beam UV-VIS spectrophotometer (PharmaSpec UV-1700, Shimadzu, Kyoto, Japan). The blank sample was prepared with methanol and treated identically to the test sample. Three readings per sample were taken. The result was expressed in mg gallic acid equivalents (GAE) $100 \mu \mathrm{L}^{-1} \mathrm{EO}$.

\subsubsection{Determination of Antioxidant Capacity}

The Trolox equivalent antioxidant capacity assay was used to measure the antioxidant capacity of tarragon essential oil; it was performed according to the method described by Semeniuc et al. (2018) [5]. The stock solution was prepared by mixing equal volumes of $7.4 \mathrm{mM}$ ABTS aqueous solution and $2.6 \mathrm{mM}$ potassium persulfate aqueous solution and allowing them to react for $12 \mathrm{~h}$ at room temperature in the dark. The working solution was prepared by mixing $1 \mathrm{~mL}$ of stock solution with $60 \mathrm{~mL}$ of methanol to obtain an absorbance of $1.1 \pm 0.02$ units at $734 \mathrm{~nm}$.

One hundred fifty microliters of the test sample (dilution of tarragon essential oil with methanol, 1:100 $(v / v))$ were transferred into a 16-mL glass bottle with a rubber stopper. Then $2850 \mu \mathrm{L}$ of ABTS working solution were added and vortexed (Vortex V-1 Plus, Biosan Ltd., Riga, Latvia). The incubation of the test sample was carried out in the dark at room temperature for $2 \mathrm{~h}$. The absorbance value was read at $734 \mathrm{~nm}$ against methanol using a double-beam UV-VIS spectrophotometer (PharmaSpec UV-1700, Shimadzu, Kyoto, Japan). The blank sample was prepared with methanol and treated identically to the test sample. Three readings per sample were taken. The absorbance value of the test 
sample was extracted from the absorbance value of the blank sample; the final result was expressed in $\mu \mathrm{M}$ Trolox equivalent (TE) $\mathrm{mL}^{-1} \mathrm{EO}$.

\subsection{Bacterial Strains}

The following microorganisms were tested: Staphylococcus aureus (ATCC 25923, Microbiologics Inc., St. Cloud, MN, USA), Escherichia coli (ATCC 25922, Microbiologics Inc., St. Cloud, MN, USA), Salmonella enteritidis (ATCC 13076, Microbiologics Inc., St. Cloud, MN, USA), and Listeria monocytogenes (ATCC 19114, Microbiologics Inc., St. Cloud, MN, USA). Each strain was grown into a test tube containing $10 \mathrm{~mL}$ sterile nutrient broth (Oxoid Ltd., Basingstoke, Hampshire, UK) at $37^{\circ} \mathrm{C}$ for $24 \mathrm{~h}$ in the case of S. aureus, E. coli, and S. enteritidis and at $37^{\circ} \mathrm{C}$ for $48 \mathrm{~h}$ in the case of L. monocytogenes. The purity of the inoculum solution was confirmed by plating on appropriate selective media and microscopic examination of the Gram-stained smear (Optika microscope, B-252, M.A.D. Apparecchiature Scientifiche, Milan, Italy). A loopful of the inoculum solution was transferred by streaking onto a selective medium: (1) Baird-Parker agar base supplemented with Egg Yolk Tellurite Emulsion (Oxoid Ltd., Basingstoke, Hampshire, UK) for S. aureus, (2) TBX agar (Oxoid Ltd., Basingstoke, Hampshire, UK) for E. coli, (3) XLD agar (Oxoid Ltd., Basingstoke, Hampshire, UK) for S. enteritidis, and (4) Palcam agar base (Oxoid Ltd., Basingstoke, Hampshire, UK) with added Palcam selective supplement for L. monocytogenes. Plates were then incubated at $37^{\circ} \mathrm{C}$ for $24 \mathrm{~h}$ (in the case of S. aureus, E. coli, and S. enteritidis) and $48 \mathrm{~h}$ (in the case of L. monocytogenes). Bacterial morphology was confirmed by optical microscopy. Several colonies were collected with a sterile inoculating loop, transferred into sterile saline solution $\left(8.5 \mathrm{~g} \mathrm{~L}^{-1}\right)$, and adjusted to match the turbidity of a McFarland 0.5 standard $\left(1.5 \times 10^{8} \mathrm{CFU} \mathrm{mL}^{-1}\right)$ [25]. Then, three serial 10-fold dilutions $\left(10^{7}, 10^{6}\right.$, and $\left.10^{5} \mathrm{CFU} \mathrm{mL}{ }^{-1}\right)$ were prepared using the sterile saline solution as diluent.

\subsubsection{Kirby-Bauer Disk Diffusion Test}

The test was performed according to the method described by Semeniuc et al. (2017) [26]. The tarragon essential oil was assessed against all bacteria using 9-mm sterile paper disks (ANTF-009-1K0, PRAT DUMAS, France). Gentamicin $\left(0.4 \mathrm{mg} \mathrm{mL}^{-1}\right.$ in saline solution) was used as a positive control. One hundred microliters of the inoculum solution $\left(1.5 \times 10^{8} \mathrm{CFU} \mathrm{mL}{ }^{-1}\right)$ were dispersed over the entire surface of the Mueller-Hinton agar plate (Sifin Diagnostics GmbH, Berlin, Germany) using a Drigalski spatula. A sterile paper disk was placed in the middle of a Petri dish, and $40 \mu \mathrm{L}$ of tarragon essential oil were released on it. Plates were then incubated at $37^{\circ} \mathrm{C}$ for $24 \mathrm{~h}$ (in the case of S. aureus, E. coli, and S. enteritidis) and $48 \mathrm{~h}$ (in the case of L. monocytogenes). A digital caliper (Powerfix Profi Z22855, Milomex Ltd., Bedfordshire, UK) was used to measure the inhibition zone diameter. Three replicates were run for each sample. The result was expressed in millimeters.

\subsubsection{Minimum Inhibitory Concentration (MIC) Test}

The test was performed according to the method described by Semeniuc et al. (2018) [5]. Eight parts $50 \%$ ethanol solution and one part Tween 80 were mixed with one part of tarragon essential oil. Sterile nutrient broth $(100 \mu \mathrm{L})$ and the mixture of essential oil $(100 \mu \mathrm{L})$ were added into the first well of a 96-well microtiter plate. Serial 11-fold dilutions were obtained by pipetting $100 \mu \mathrm{L}$ from well to well (on the same row), while $100 \mu \mathrm{L}$ were discarded from the last well of the row. Next, a volume of $10 \mu \mathrm{L}$ inoculum solution $\left(1.5 \times 10^{5} \mathrm{CFU} \mathrm{mL} \mathrm{mL}^{-1}\right)$ was added to each well. Concentrations ranging from 0.01 to $47.62 \mu \mathrm{L} \mathrm{EO} \mathrm{mL}{ }^{-1}$ were thus reached. For the negative control, eight parts $50 \%$ ethanol solution and one part Tween 80 were mixed with one part saline solution, while gentamicin $\left(0.4 \mathrm{mg} \mathrm{mL}^{-1}\right.$ in saline solution) was considered the positive control. Microplates were incubated at $37^{\circ} \mathrm{C}$ for $21 \mathrm{~h}$ (in the case of S. aureus, E. coli, and S. enteritidis) and $45 \mathrm{~h}$ (in the case of L. monocytogenes). A volume of $20 \mu \mathrm{L}$ resazurin aqueous solution $\left(0.2 \mathrm{mg} \mathrm{mL}^{-1}\right)$ was added to each well. Microplates were subsequently incubated at $37^{\circ} \mathrm{C}$ for $2 \mathrm{~h}$ (in the case of S. aureus, E. coli, and S. enteritidis) and $23 \mathrm{~h}$ (in the case of $L$. monocytogenes). The lowest concentration that retained the blue color was considered the concentration 
that completely inhibited bacterial growth (MIC). Three replicates were run for each sample. The result was expressed in $\mu \mathrm{LEO} \mathrm{mL}-1$ and $\mu \mathrm{g}$ gentamicin (GE) $\mathrm{mL}^{-1}$.

\subsubsection{Minimum Bactericidal Concentration (MBC) Test}

The test was performed according to the method described by Semeniuc et al. (2018) [5]. To determine the minimum bactericidal concentration (MBC), $10 \mu \mathrm{L}$ of the dilution representing the MIC and the more concentrated two dilutions were plated on the appropriate selective media (Baird-Parker agar base supplemented with Egg Yolk Tellurite Emulsion for S. aureus, TBX agar for E. coli, XLD agar for S. enteritidis, and Palcam agar base with added Palcam selective supplement for L. monocytogenes) using a Drigalski spatula and incubated for $48 \mathrm{~h}$ at $37^{\circ} \mathrm{C}$. A colony counter (Colony Star 8500, Funke Gerber, Berlin, Germany) was used to determine the relative number of bacterial colonies. The lowest concentration of the antimicrobial agent causing negative growth (fewer than three colonies) was considered the concentration that completely killed bacteria (MBC). Three replicates were run for each sample. The result was expressed in $\mu \mathrm{LEO} \mathrm{mL}^{-1}$.

\subsection{Films' Preparation}

UNT films were prepared from native WPI solutions and HT films from heat-denatured WPI solutions. Film-forming solutions were obtained by dissolving 5\% $(w / w)$ WPI in distilled water, according to the modified protocol described by Badr et al. (2014) [27]. Glycerol was added as a plasticizer in filmogenic solutions, at a concentration of $5 \%(w / w)$. The WPI (Prolacta 95 LL Instant, Lactalis, France) was purchased from REDIS C.O. S.R. (Bucharest, Romania), and the glycerol from Chempur (Piekary Śląkie, Poland).

For HT films, solutions were subsequently heated for $30 \mathrm{~min}$. at $90 \pm 2{ }^{\circ} \mathrm{C}$ while being continuously stirred using a magnetic stirrer with heating (MSH-300, Biosan Ltd., Riga, Latvia). Heated solutions were then cooled at room temperature for $1.5 \mathrm{~h}$ and filtered to remove any air incorporated during stirring.

The essential oil of tarragon was added both in native WPI and heat-denatured WPI solutions in different amounts, to obtain formulations of $0.5 \%$ (F0.5), 1.0\% (F1), 1.5\% (F1.5), 2.0\% (F2), and 2.5\% (F2.5). Solutions were then homogenized at $23,000 \mathrm{rpm}$ for $2.5 \mathrm{~min}$ using a laboratory dispenser ( $\mathrm{T}$ 18 digital Ultra-Turrax, IKA-Werke GmbH \& Co. KG, Staufen, Germany). The final film-forming solutions were poured $(4.8 \mathrm{~g})$ into disposable weighing dishes $(43 \times 13 \mathrm{~mm})$ and then dried in an oven (Digitheat, J.P. Selecta S.A., Barcelona, Spain) at $37^{\circ} \mathrm{C}(42 \mathrm{~h})$. Once formed, the films were peeled off and stored individually in airtight containers, at room temperature, until analysis.

\subsubsection{Measurement of Thickness}

The thickness $(\mathrm{mm})$ of each film formulation was measured at 24 random points using a digital caliper (Powerfix Profi Z22855, Milomex Ltd., Bedfordshire, UK).

\subsubsection{Determination of Moisture Content}

The moisture content was determined using the oven-drying method by the differential weighing of the film sample before and after drying. The film specimen was cut approximately into equal quarters; each quarter was dried in an oven (Digitheat, J.P. Selecta S.A., Barcelona, Spain) at $105^{\circ} \mathrm{C}$ until constant weight. The moisture content was calculated using the following Formula (1):

$$
\text { Moisture Content }(\%)=\frac{w_{i}-w_{d}}{w_{i}} \times 100
$$

where $w_{i}$ is the initial weight of the film sample $(\mathrm{g})$ and $w_{d}$ is the oven-dry weight of the film sample (g). Four replicates were run for each film formulation. 


\subsubsection{Determination of Swelling Degree and Solubility in Water}

These parameters were determined according to a slightly modified method of Wang et al. (2010) [28]. The film specimen was cut into square pieces. A piece of the film was accurately weighed $(\sim 0.1 \mathrm{~g})$ into a $50-\mathrm{mL}$ glass beaker, and then $40 \mathrm{~mL}$ of distilled water were added. After $24 \mathrm{~h}$ of immersion at room temperature $\left(25^{\circ} \mathrm{C}\right)$, the remnant was filtered and weighed, for the determination of swelling degree or filtered and dried in an oven (Digitheat, J.P. Selecta S.A., Barcelona, Spain) at $105^{\circ} \mathrm{C}$ until constant weight, for the determination of solubility in water. The swelling degree was calculated by (2) and the solubility in water by (3):

$$
\begin{aligned}
& \text { Swelling Degree }(\%)=\frac{w_{i}-w_{f}}{w_{i}} \times 100 \\
& \text { Solubility in Water }(\%)=\frac{w_{i}-w_{d}}{w_{i}} \times 100
\end{aligned}
$$

where $w_{i}$ is the initial weight of the film sample $(\mathrm{g}), w_{f}$ is the weight of the remnant after filtration $(\mathrm{g})$, and $w_{d}$ is the oven-dry weight of the remnant $(\mathrm{g})$. Three replicates were run for each film formulation in both cases.

\subsubsection{Determination of Water Vapor Permeability (WVP)}

The WVP was determined according to the method described by Ghasemlou et al. (2013), with slight modification [29]. The film was sealed on a plastic cup (commercially available), containing $5.0 \mathrm{~g}$ of calcium chloride anhydrous $\left(\mathrm{CaCl}_{2}-0 \% \mathrm{RH}\right)$, with an exposed area of $4.0 \mathrm{~cm}^{2}$. The cup was stored at room temperature in a desiccator containing a saturated sodium chloride solution $\left(\sim 25^{\circ} \mathrm{C}\right.$, $\mathrm{NaCl}-60 \%$ relative humidity). The weight of the cup $(w)$ was recorded every hour during the first $8 \mathrm{~h}$, and every day for 14 days. The weight gain $(\Delta w)$ was plotted as a function of time. The slope (a) of each line was calculated by linear regression; the correlation coefficient was $>0.99$ at all film formulations. The WVP was calculated with the following Equation (4):

$$
W V P\left(g m m / m^{2} \text { day } k P a\right)=\frac{a \times X}{A \times \Delta p}
$$

where $a$ is the slope of the regression line, $X$ is the film thickness (mm), $A$ is the area of exposed film $\left(\mathrm{m}^{2}\right)$, and $\Delta p$ is the vapor pressure differential across the tested film (kilopascals). Three replicates were run for each film formulation.

\subsubsection{Measurement of Color}

The color was measured using an NH300 portable colorimeter (3NH, Shenzhen, China) based on the CIE L*a*b* color system. The $L^{*}$-value represents lightness and ranges from zero (the darkest black) to 100 (the brightest white). The $a^{*}$-value represents "redness" or "greenness" and ranges from +60 for absolute red to -60 for absolute green, while $b^{*}$-value represents "yellowness" or "blueness" and ranges from +60 for absolute yellow to -60 for absolute blue. Measurements were performed using a D65 illuminant with an opening of $8 \mathrm{~mm}$ and a $10^{\circ}$ standard observer. The colorimeter was subjected to automatic black and white calibration. The film specimen was placed on the surface of a standard white plate $\left(L_{s}^{*}=90.75, a_{s}^{*}=-0.082, b_{s}^{*}=-2.71\right)$ before measuring. The total color difference $\left(\Delta E^{*}\right)$ was calculated by (5):

$$
\Delta E^{*}=\sqrt{\left(L^{*}-L_{s}^{*}\right)^{2}+\left(a^{*}-a_{s}^{*}\right)^{2}+\left(b^{*}-b_{s}^{*}\right)^{2}}
$$

where $L^{*}, a^{*}$, and $b^{*}$ are the color values of the film sample and $L_{s}^{*}, a_{s}^{*}$, and $b_{s}^{*}$ of the standard white plate. Twelve readings were taken on each film formulation. 


\subsubsection{Measurement of Light Transmittance and Transparency}

Light transmittance percentage and transparency value were determined using a double-beam UV-VIS spectrophotometer (PharmaSpec UV-1700, Shimadzu, Kyoto, Japan) by reading the absorbance of the film sample at wavelengths between $200-800 \mathrm{~nm}$. Transmittance is the percent of incident light that passes through a material sample and is determined by the effectiveness of the absorption and scattering of light by the material. Transparent material has a transmittance above 90\% [30].

The film specimen was cut into 3 strips $(0.7 \mathrm{~cm} \times 3 \mathrm{~cm})$. Each strip was placed in a quartz cuvette (100-QS, 10 mm lightpath, Hellma Analytics, Müllheim, Germany), and its absorbance read against an empty cuvette. Conversion of the absorbance value to percent transmittance was done using the Lambert-Beer Equation (6):

$$
\text { Light Transmittance }(\%)=\operatorname{antilog}_{10}(2-A)
$$

where $A$ is the absorbance value of the film strip.

The relative transparency of film strip was measured at $600 \mathrm{~nm}$, and calculated with the formula [31] (7):

$$
\text { Transparency }(A 600 / \mathrm{mm})=\frac{A 600}{X}
$$

where $A 600$ is the absorbance value at $600 \mathrm{~nm}$ and $X$ is the film thickness (mm). Three readings were taken on each film formulation.

\subsubsection{Puncture Test}

The mechanical properties of the film (puncture resistance (PR) and puncture deformation (PD)) were determined by the puncture test proposed by Mitrea et al. (2020), using a texture analyzer (CT3, Brookfield Engineering Laboratories Inc., Middleboro, MA, USA) [32]. The film specimen was placed in the middle of two metallic washers (commercially available), with a hole of $10 \mathrm{~mm}$ in diameter, and fixed between them with two clamps. The film support fixture was then placed onto the base table and fastened into position. The puncture head (a cylindrical rod of $2 \mathrm{~mm}$ in diameter-TA39), was set to a target distance of $5.0 \mathrm{~mm}$ with a speed of $0.5 \mathrm{~mm} / \mathrm{s}$. Measurements were performed in four replicates for each formulation type. To avoid any effect of thickness fluctuation, the measured values were divided by the thickness of the film and reported as N/mm for PR and as $\mathrm{mm}$ for PD.

\subsection{Statistical Analysis}

Data analysis was carried out using Minitab statistical software (version 16.1.0; LEAD Technologies, Inc., Charlotte, NC, USA). The effects of heat treatment of the film-forming solution and the addition of tarragon essential oil on thickness, moisture content, swelling degree, solubility in water, WVP, color, light transmittance, transparency, PR, and PD of the film were analyzed using analysis of variance (ANOVA) by applying a general linear model (see Tables S1-S4 in Supplementary Material). Post hoc pairwise comparisons were performed with Tukey's test at a 95\% confidence level $(p<0.05)$. Statistical significance of the effects was interpreted as follows: $p \geq 0.05^{\mathrm{NS}}$, not significant; $p<0.05^{*}$, significant; $p<0.01^{* *}$, very significant; $p<0.001^{* * *}$, extremely significant. The percentage contribution of each factor and their interaction was calculated using eta-squared $\left(\eta^{2}\right)$.

\section{Results}

\subsection{Chemical and Biological Properties of Tarragon Essential Oil}

The essential oil extracted from dried leaves of tarragon showed an extraction yield of $0.62 \%(v / w)$, total phenolic content of $2.3 \pm 0.099 \mathrm{mg} \mathrm{GAE} 100 \mu \mathrm{L}^{-1} \mathrm{EO}$, and antioxidant capacity of $31.0 \pm 0.291 \mu \mathrm{M}$ TE $\mathrm{mL}^{-1} \mathrm{EO}$. 
The volatile compounds detected in tarragon essential oil by ITEX/GC-MS analysis are listed in Table 1. Sixteen compounds, representing $100 \%$ of the total detected constituents, were identified in the essential oil of tarragon and grouped based on their chemical structure into four classes (monoterpene hydrocarbons- $\mathrm{C} 1$, phenylpropanoids- $\mathrm{C} 2$, oxygenated monoterpenes- $\mathrm{C} 3$, and aliphatic aldehydes-C4). The most abundant constituents were monoterpene hydrocarbons (96.66\%), followed by phenylpropanoids $(2.18 \%)$, oxygenated monoterpenes $(0.99 \%)$, and aliphatic aldehydes $(0.18 \%)$. The major components identified in tarragon essential oil were sabinene $(74.98 \%), \gamma$-terpinene $(3.80 \%)$, D-limonene (3.69\%), $\beta$-myrcene (3.38\%), 4-carene (2.58\%), and $\alpha$-phellandrene (2.27\%), all of them belonging to the monoterpene hydrocarbons' class.

Table 1. Retention times ( $\mathrm{min}$ ) and relative contents (\%) of volatile constituents identified in tarragon essential oil.

\begin{tabular}{ccccc}
\hline Crt. No. & Compound & Chemical Class & Retention Time & Relative Content \\
\hline 1 & Hexanal & A.A. & 5.451 & 0.18 \\
2 & $\alpha$-Phellandrene & M.C. & 9.695 & 2.27 \\
3 & $\alpha$-Pinene & M.C. & 9.959 & 1.35 \\
4 & Sabinene & M.C. & 11.537 & 74.98 \\
5 & $\beta$-Pinene & M.C. & 11.709 & 1.76 \\
6 & $\beta$-Myrcene & M.C. & 12.224 & 3.38 \\
7 & 4-Carene & M.C. & 13.306 & 2.58 \\
8 & $o-C y m e n e$ & M.C. & 13.627 & 1.10 \\
9 & D-Limonene & M.C. & 13.806 & 3.69 \\
10 & 1,8-cineole & O.M. & 13.947 & 0.10 \\
11 & trans- $\beta$-Ocimene & M.C. & 14.119 & 0.70 \\
12 & cis- $\beta$-Ocimene & M.C. & 14.538 & 0.36 \\
13 & $\gamma$-Terpinene & M.C. & 14.990 & 3.80 \\
14 & Terpinolene & M.C. & 16.083 & 0.69 \\
15 & trans-4-Thujanol & O.M. & 19.882 & 0.89 \\
16 & Isoeugenol methyl ether & Phe.P. & 27.898 & 2.18 \\
- & TOTAL & - & - & 100.00 \\
\hline
\end{tabular}

A.A.—aliphatic aldehyde; M.C.—-monoterpene hydrocarbon; O.M.—oxygenated monoterpene; Phe.P.—phenylpropanoid.

Results of the Kirby-Bauer disk diffusion test are presented in Table 2. The essential oil of tarragon exhibited the highest inhibitory effect against S. enteritidis, followed by S. aureus, E. coli, and L. monocytogenes.

Table 2. Diameters of inhibition zones $(\mathrm{mm})$ of bacterial strains produced by the tarragon essential oil and gentamicin.

\begin{tabular}{ccc}
\hline Bacterial Strain & Tarragon Essential Oil & Gentamicin \\
\hline E. coli (ATCC 25922) & $12.03 \pm 0.47$ & $25.27 \pm 0.08$ \\
S. enteritidis (ATCC 13076) & $14.41 \pm 0.29$ & $23.39 \pm 0.03$ \\
S. aureus (ATCC 25923) & $13.53 \pm 0.38$ & $25.77 \pm 0.39$ \\
L. monocytogenes (ATCC 19114) & $11.42 \pm 0.27$ & $26.67 \pm 1.68$ \\
\hline
\end{tabular}

Values are expressed as mean \pm standard deviation of three replicates.

Table 3 summarizes the results of MIC and MBC tests. The lower the MIC/MBC value, the higher the antibacterial activity of essential oil [26]. The essential oil of tarragon revealed both bacteriostatic and bactericidal properties as follows: Against E. coli $>$ L. monocytogenes $>$ S. enteritidis $>$ S. aureus. 
Table 3. Minimum inhibitory concentration ( $\mathrm{MIC}, \mu \mathrm{L} \mathrm{EO} \mathrm{mL}^{-1}$ ) and minimum bactericidal

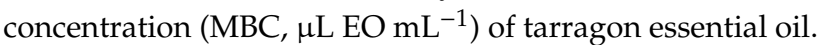

\begin{tabular}{ccc}
\hline \multirow{2}{*}{ Bacterial Strain } & \multicolumn{2}{c}{ Tarragon Essential Oil } \\
\cline { 2 - 3 } & MIC & MBC \\
\hline E. coli (ATCC 25922) & $5.14 \pm 0.0$ & $5.14 \pm 0.0$ \\
S. enteritidis (ATCC 13076) & $10.80 \pm 0.0$ & $10.80 \pm 0.0$ \\
S. aureus (ATCC 25923) & $10.80 \pm 0.0$ & $22.68 \pm 0.0$ \\
L. monocytogenes (ATCC 19114) & $5.14 \pm 0.0$ & $10.80 \pm 0.0$ \\
\hline
\end{tabular}

Values are expressed as mean \pm standard deviation of three replicates. The MICs of gentamicin for $E$. coli (ATCC 25922), S. enteritidis (ATCC 13076), S. aureus (ATCC 25923), and L. monocytogenes (ATCC 19114) were 0.50, 0.11, 0.05, and $0.05 \mu \mathrm{g} \mathrm{GE} \mathrm{mL}^{-1}$, respectively.

\subsection{Physical and Mechanical Properties of Films}

\subsubsection{Films' Appearance}

Figure 1 shows the surface images of UNT and HT formulations. Both UNT and HT films were flexible, yellowish, and semi-transparent; the changes in color and transparency with the amount of added tarragon essential oil are discussed in the Sections 3.2.6 and 3.2.7.

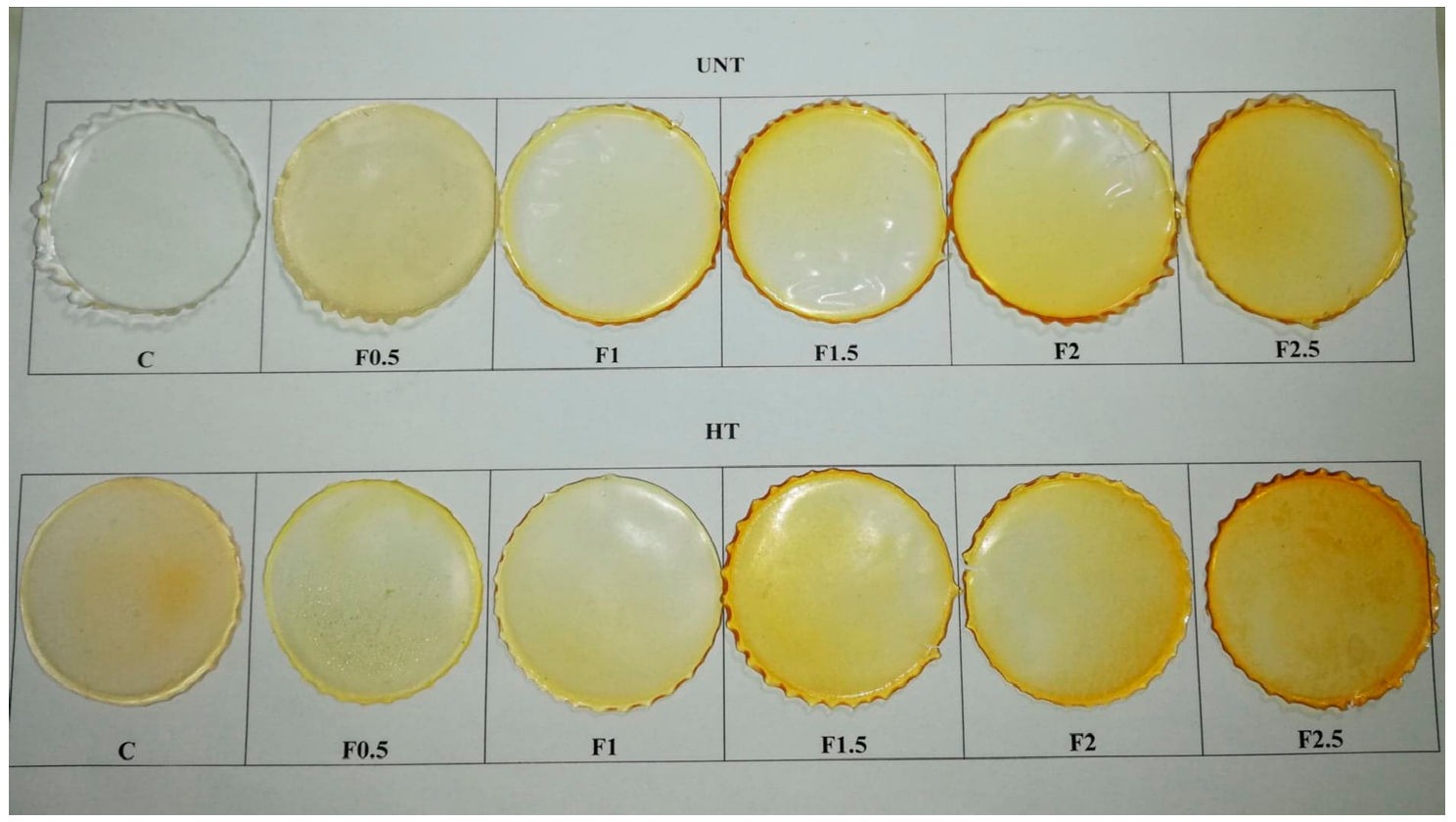

Figure 1. Surface images of UNT and HT formulations. C-control film; F0.5-film with $0.5 \%$ tarragon essential oil; F1-film with 1\% tarragon essential oil; F1.5-film with 1.5\% tarragon essential oil; F2-film with $2 \%$ tarragon essential oil; F2.5-film with $2.5 \%$ tarragon essential oil.

Surfaces of films were smooth, with no evidence of pores, cracks, or fissures. The appearance of the two sides of the film was different for both UNT and HT films; the film side facing the casting dish was dull, while the other was shiny. This indicates some phase separation during drying, visible on UNT films as very fine oil droplets at the surface. On HT films, formulations F1.5, F2, and F2.5 showed discontinuities, probably due to oil droplet flocculation.

HT films were easily detached by the casting dishes, while UNT films were rather sticky.

Values obtained for the thickness of UNT and HT formulations are shown in Figure 2. The heat treatment of the film-forming solution had a significant effect $\left(p<0.001^{* * *}\right)$ on film thickness, with a contribution of $21.8 \%$, the HT film being thicker than the UNT one (see Table S1 in Supplementary Material). In contrast, the addition of tarragon essential oil in a concentration of up to $2.5 \%$ did not 
have a significant effect $\left(p>0.05^{\mathrm{NS}}\right.$; contribution of $\left.1 \%\right)$ on the film thickness. In UNT films, thickness ranged between 0.43 and $0.44 \mathrm{~mm}$, while in HT ones, between 0.45 and $0.46 \mathrm{~mm}$.

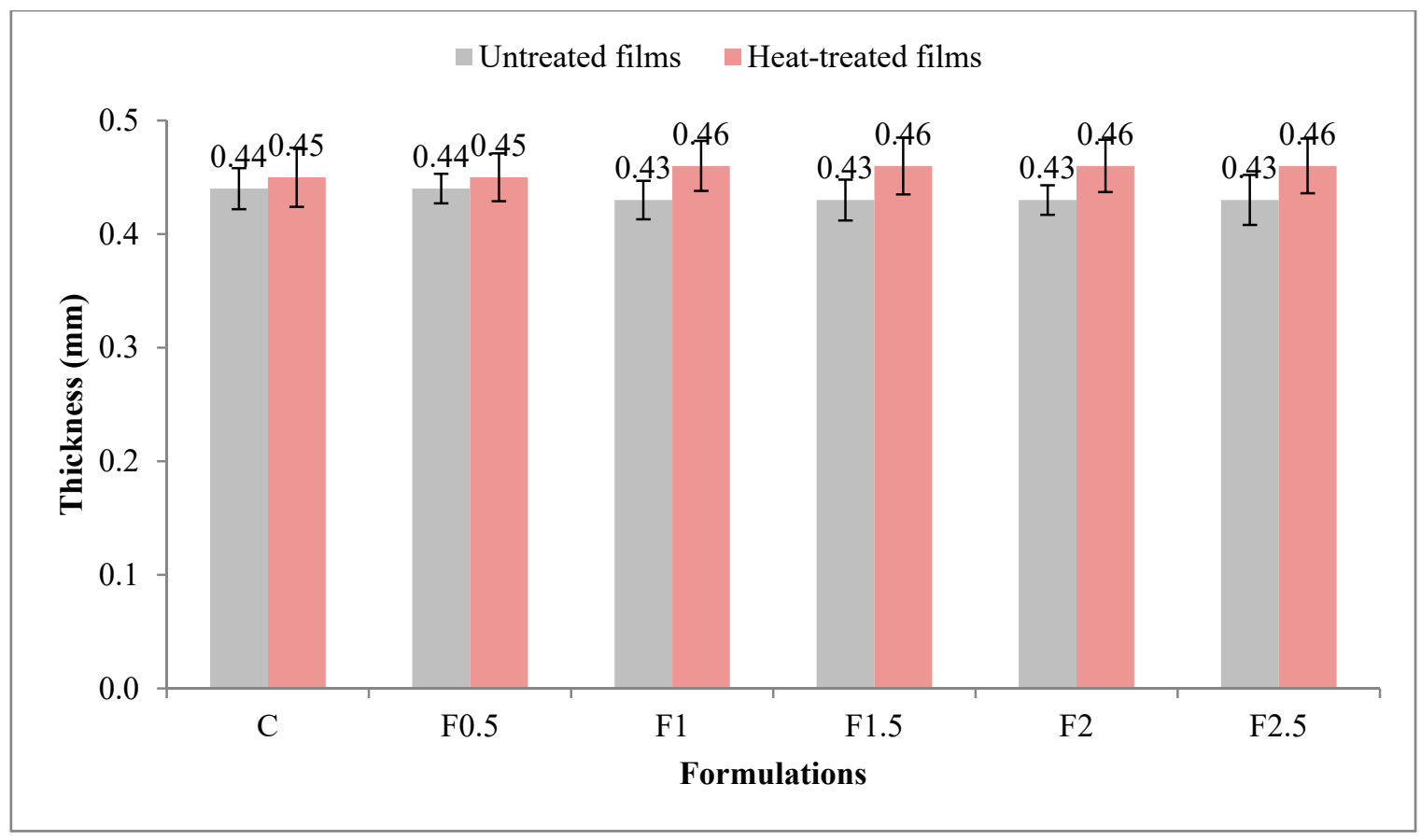

Figure 2. Variation in film thickness with heat treatment and formulation. C-control film; F0.5-film with $0.5 \%$ tarragon essential oil; F1-film with $1 \%$ tarragon essential oil; F1.5-film with $1.5 \%$ tarragon essential oil; F2-film with $2 \%$ tarragon essential oil; F2.5-film with $2.5 \%$ tarragon essential oil. Values are expressed as mean \pm standard deviation of 24 replicates.

\subsubsection{Moisture Content}

This parameter indicates the total void volume occupied by water molecules in the network microstructure of the film [28]. Figure 3 shows moisture-content values for UNT and HT films. The moisture content was significantly higher $(p<0.001 * * *)$ in the HT film compared to the UNT one, the contribution of the heat treatment of the film-forming solution being $45.2 \%$ (see Table S1 in Supplementary Material). The addition of tarragon essential oil also significantly influenced $(p<$ $0.001^{* * *}$ ) the moisture content of the film, with a contribution of $23.7 \%$, resulting in its increase with the added amount. The moisture content showed values between 40.4 and $50.6 \%$ in UNT films and between 48.1 and $56.4 \%$ in HT ones.

\subsubsection{Swelling Degree}

Swelling is an undesirable property for an edible film, especially if destined for packaging of food with high moisture content [33]. Figure 4 illustrates the values for swelling degree in UNT and HT films. The swelling degree was significantly affected $(p<0.001 * *)$ by heat treatment of the film-forming solution, with a contribution of $68.1 \%$ (see Table S1 in Supplementary Material). The value of this parameter was higher in HT film compared to UNT one. The contribution of tarragon essential oil addition was also significant $\left(p<0.01^{* *}\right)$ but lower as a share $(9.2 \%)$. The swelling degree value ranged, with the addition of tarragon essential oil, between 100.4 and $100.6 \%$ in UNT films, and between 100.9 and $101.9 \%$ in HT ones. A much higher swelling degree, approximately $350 \%$, was found by Wang et al. (2010) in edible film prepared with 10\% WPI and 5\% glycerol [28]. 


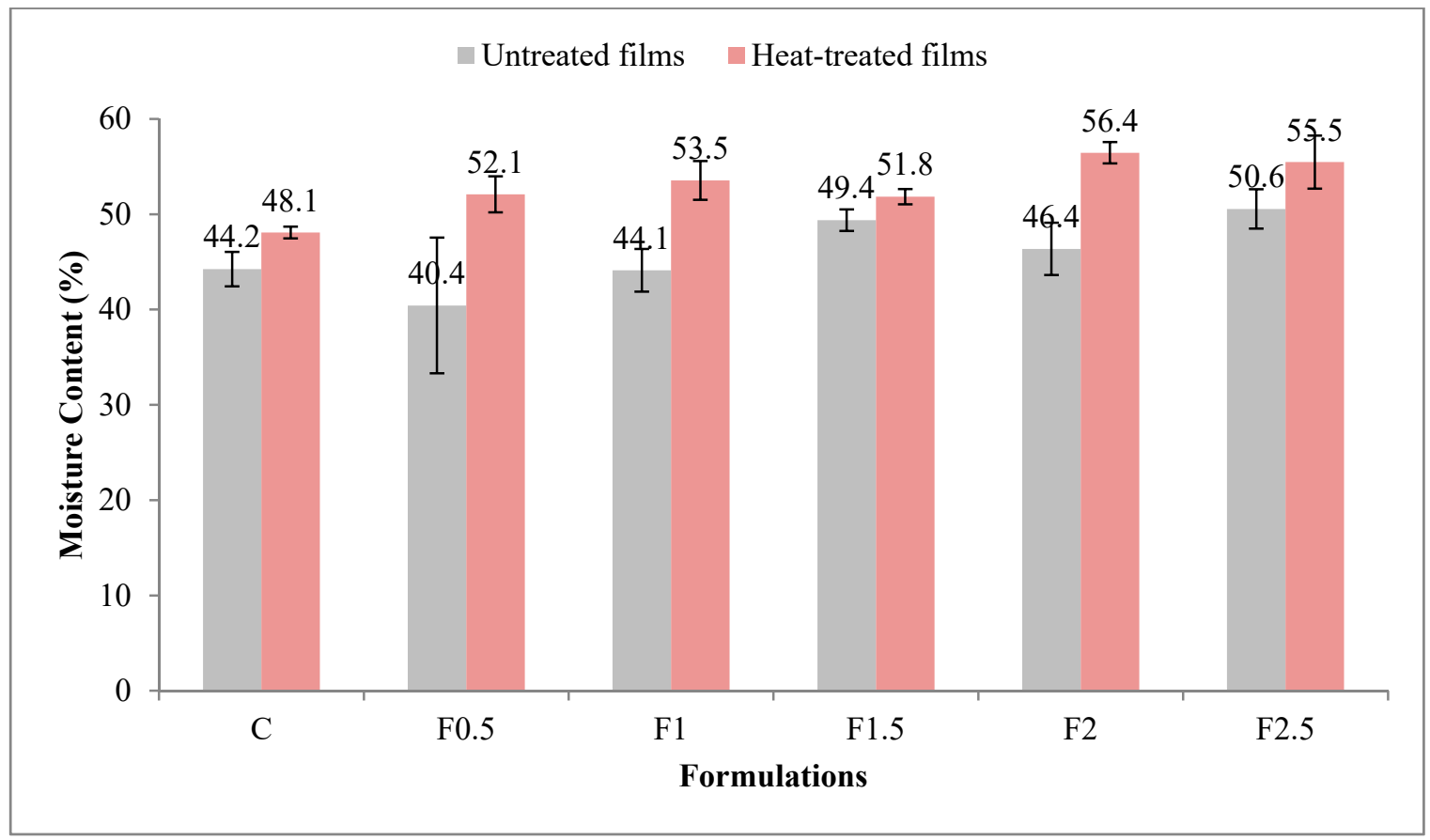

Figure 3. Variation in moisture content with heat treatment and formulation. C-control film; F0.5-film with $0.5 \%$ tarragon essential oil; F1-film with $1 \%$ tarragon essential oil; F1.5-film with $1.5 \%$ tarragon essential oil; F2-film with $2 \%$ tarragon essential oil; F2.5-film with $2.5 \%$ tarragon essential oil. Values are expressed as mean \pm standard deviation of four replicates.

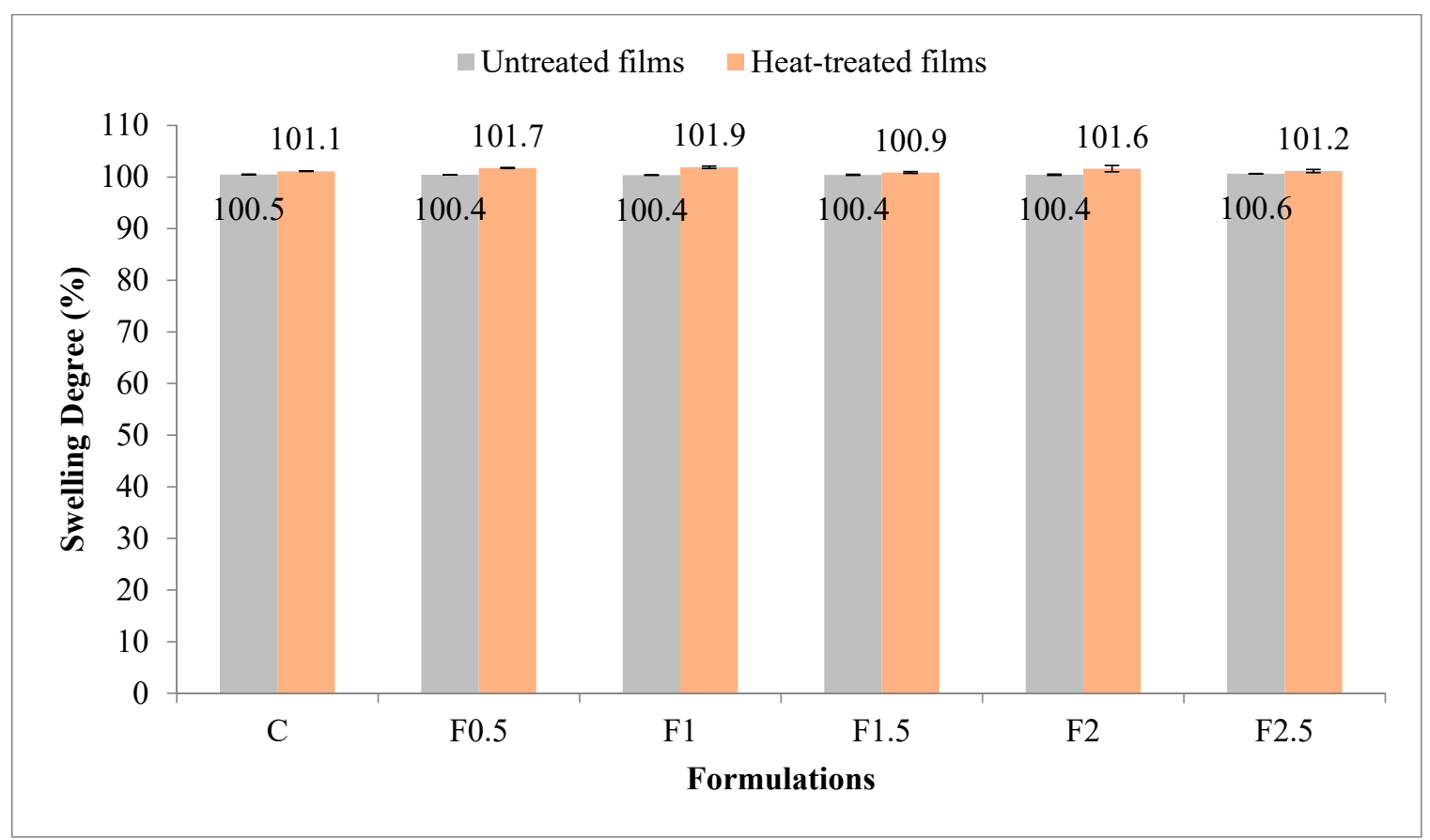

Figure 4. Variation in swelling degree with heat treatment and formulation. C-control film; F0.5-film with $0.5 \%$ tarragon essential oil; F1-film with $1 \%$ tarragon essential oil; F1.5-film with $1.5 \%$ tarragon essential oil; F2-film with $2 \%$ tarragon essential oil; F2.5-film with $2.5 \%$ tarragon essential oil. Values are expressed as mean \pm standard deviation of three replicates. 


\subsubsection{Solubility in Water}

The solubility in water is a parameter related to the hydrophilicity of film [34]. Values obtained for the solubility in water of UNT and HT formulations are shown in Figure 5. In UNT films, solubility in water ranged from 95.6 to $98.9 \%$, and in HT ones, from 95.0 to $97.4 \%$. Ramos et al. (2012) reported a lower value of solubility in water, $67.6 \%$, in their edible film prepared with $10 \%$ WPI and $5 \%$ glycerol [35].

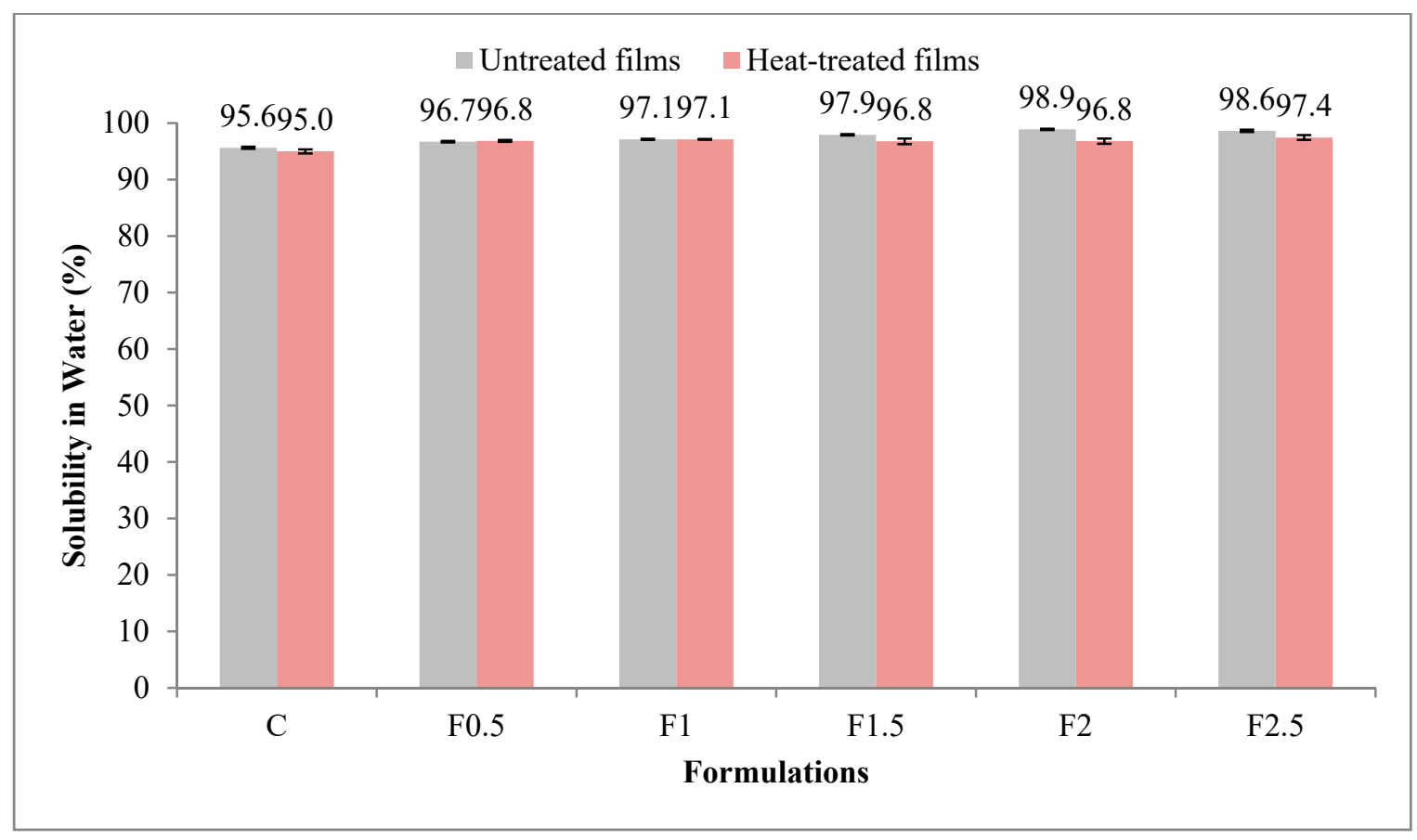

Figure 5. Variation of solubility in water with heat treatment and formulation. C-control film; F0.5-film with $0.5 \%$ tarragon essential oil; F1-film with $1 \%$ tarragon essential oil; F1.5-film with $1.5 \%$ tarragon essential oil; F2-film with $2 \%$ tarragon essential oil; F2.5-film with $2.5 \%$ tarragon essential oil. Values are expressed as mean \pm standard deviation of three replicates.

The solubility in water was significantly lower $\left(p<0.001^{* * *}\right)$ in the HT film as opposed to UNT one, indicating lower hydrophilicity (see Table S1 in Supplementary Material); an explanation may be that protein agglomerates have blocked the micropaths in the network microstructure [28]. The contribution of the thermic factor was $14.5 \%$. The value of solubility in water significantly increased $\left(p<0.001^{* * *}\right)$ with the addition of tarragon essential oil, thus enhancing the film hydrophilicity, and the contribution of this factor was higher, of $68.7 \%$.

\subsubsection{Water Vapor Permeability (WVP)}

The WVP of a film is directly related to the micropaths in its network microstructure [34]; the higher the WVP value, the more permeable the film is to moisture. Figure 6 displays the WVP values for both UNT and HT films. In UNT films, WVP ranged between 6.7 and $8.7 \mathrm{~g} \mathrm{~mm} / \mathrm{m}^{2}$ day $\mathrm{kPa}$ while in HT ones, between 7.3 and $9.6 \mathrm{~g} \mathrm{~mm} / \mathrm{m}^{2}$ day $\mathrm{kPa}$. Comparable values of WVP were reported by Pérez-Gago et al. (1999) in edible films prepared with $5 \%$ WPI and $12 \%$ glycerol, of $5.1 \mathrm{~g} \mathrm{~mm} / \mathrm{m}^{2}$ day $\mathrm{kPa}$ in the UNT film and $5.0 \mathrm{~g} \mathrm{~mm} / \mathrm{m}^{2}$ day $\mathrm{kPa}$ in the HT film [36]. Higher levels of WVP were found by Wang et al. (2010) and Ramos et al. (2012) in their edible films prepared with 10\% WPI and 5\% glycerol, of $22.0 \mathrm{~g} \mathrm{~mm} / \mathrm{m}^{2}$ day $\mathrm{kPa}$ and $10.1 \mathrm{~g} \mathrm{~mm} / \mathrm{m}^{2}$ day $\mathrm{kPa}$, respectively [28,35]. 


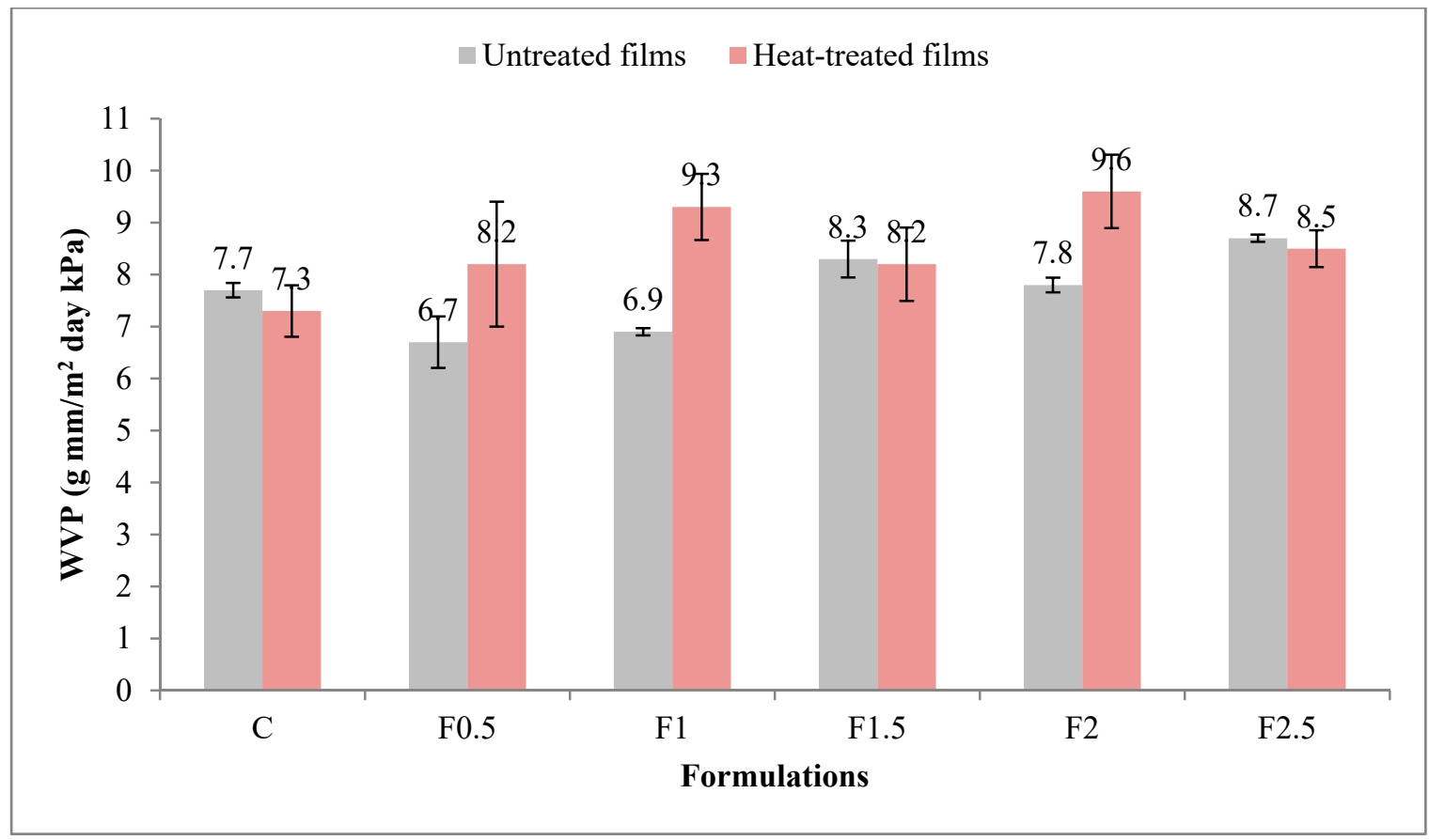

Figure 6. Variation in water vapor permeability (WVP) with heat treatment and formulation. C-control film; F0.5-film with $0.5 \%$ tarragon essential oil; F1-film with $1 \%$ tarragon essential oil; F1.5-film with $1.5 \%$ tarragon essential oil; F2-film with $2 \%$ tarragon essential oil; F2.5-film with $2.5 \%$ tarragon essential oil. Values are expressed as mean \pm standard deviation of three replicates.

The WVP was significantly influenced $\left(p<0.01^{* *}\right)$ by heat treatment of the film-forming solution, with a contribution of $19.9 \%$ (see Table S1 in Supplementary Material). Its value was higher in HT film, thus revealing a higher permeability to moisture than the UNT film. The WVP was also significantly influenced $\left(p<0.05^{*}\right)$ by the addition of tarragon essential oil (contribution of $27.8 \%$ ), increasing with the added amount. Consequently, the moisture barrier properties of the film were diminished.

\subsubsection{Color}

Color attributes $\left(L^{*}, a^{*}, b^{*}\right.$, and $\left.\Delta E^{*}\right)$ for UNT and HT films, containing various levels of tarragon essential oil, are shown in Figure $7 \mathrm{a}, \mathrm{b}$. The $\Delta E^{*}$ provides a good measure of the color difference since it takes into account all three color parameters: Lightness $\left(L^{*}\right)$, red-green $\left(a^{*}\right)$, and yellow-blue $\left(b^{*}\right)$ components [31]. The heat treatment of the film-forming solution had a significant effect $(p<0.001 * * *)$ on the color parameters of film, with a contribution of $27.5 \%$ for $L^{*}$, of $13.3 \%$ for $a^{*}$, of $16.6 \%$ for $b^{*}$, and of $20.2 \%$ for $\Delta E^{*}$ (see Table S2 in Supplementary Material). Values for $L^{*}$ and $a^{*}$ were lower in HT film and values for $\mathrm{b}^{*}$ and $\Delta E^{*}$, in UNT one. Therefore, the HT film had a darker and more yellowish color compared to UNT one but less reddish. The addition of tarragon essential oil also had a significant effect $\left(p<0.001^{* * *}\right)$ on the color parameters of film, the contribution of this factor being higher, of $30.6 \%$ for $L^{*}$, of $60.4 \%$ for $a^{*}$, of $61.9 \%$ for $b^{*}$, and of $65.0 \%$ for $\Delta E^{*}$. $L^{*}$-values oscillated with the addition of tarragon essential oil and $a^{*}-, b^{*}$-, and $\Delta E^{*}$-values increased, resulting in a red-yellowish color of the film. In UNT films, $L^{*}$-value ranged between 84.46 (C-control film) and 79.90 (F2.5), $a^{*}$-value between 1.66 (C) and 4.02 (F2.5), $b^{*}$-value between 14.75 (C) and 22.89 (F2.5), while $\Delta E^{*}$-value was between 18.67 (C) and 28.11 (F2.5). With regard to HT films, $L^{*}$-value ranged between 79.50 (C) and 78.53 (F2.5), $a^{*}$-value between 1.88 (C) and 3.35 (F2.5), $b^{*}$-value between 16.01 (C) and 22.62 (F2.5), while $\Delta E^{*}$-value was between $21.93(\mathrm{C})$ and 28.34 (F2.5). 


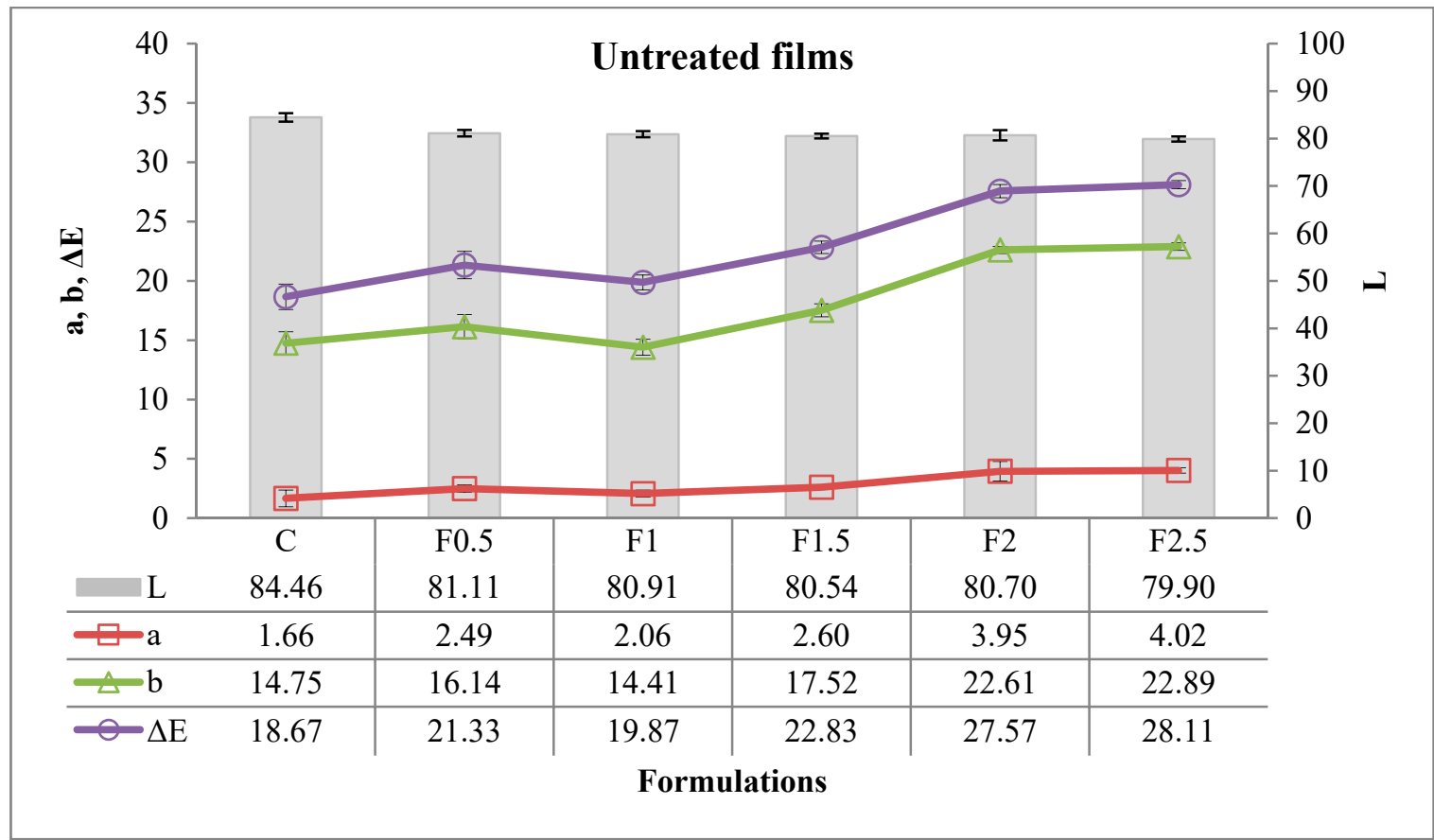

(a)

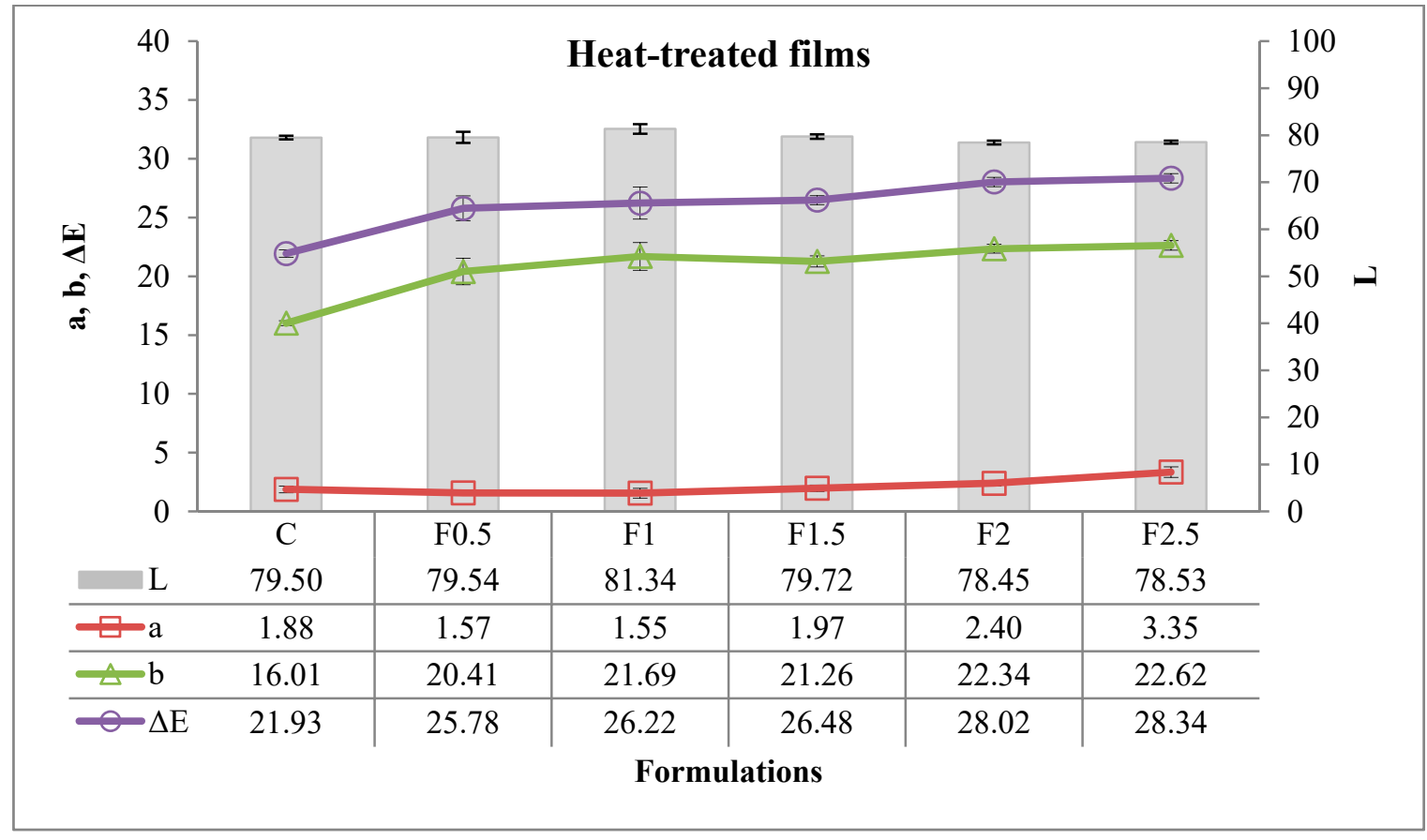

(b)

Figure 7. Color attributes of edible films. (a) Untreated, (b) heat-treated. C-control film; F0.5-film with $0.5 \%$ tarragon essential oil; F1-film with $1 \%$ tarragon essential oil; F1.5-film with $1.5 \%$ tarragon essential oil; F2-film with $2 \%$ tarragon essential oil; F2.5-film with $2.5 \%$ tarragon essential oil. Values are expressed as mean \pm standard deviation of 12 replicates.

\subsubsection{Light Transmittance and Transparency}

The ultraviolet (UV) and light-visible (VIS) barrier properties of the film were measured at various wavelengths (in the range of 200 to $800 \mathrm{~nm}$ ), using a double-beam UV-VIS spectrophotometer. Good 
barrier properties to UV and VIS light are indicated by low transmittance values in the range of 200-350 $\mathrm{nm}$ and $400-800 \mathrm{~nm}$, respectively.

Light transmittance percentages in the UV-VIS range, as well as transparency values related to UNT and HT films, are shown in Figure 8a,b. The heat treatment of the film-forming solution had a significant effect $\left(p<0.001^{* * *}\right)$ on the transmittance of film at all analyzed wavelengths, but with different contributions: Of $66.6 \%$ at $200 \mathrm{~nm}, 71.9 \%$ at $250 \mathrm{~nm}, 58.4 \%$ at $300 \mathrm{~nm}, 19.2 \%$ at $350 \mathrm{~nm}, 28.0 \%$ at $400 \mathrm{~nm}, 28.1 \%$ at $450 \mathrm{~nm}, 28.1 \%$ at $500 \mathrm{~nm}, 28.8 \%$ at $550 \mathrm{~nm}, 30.1 \%$ at $600 \mathrm{~nm}, 30.1 \%$ at $650 \mathrm{~nm}, 30.3 \%$ at $700 \mathrm{~nm}, 30.0 \%$ at $750 \mathrm{~nm}$, and $29.7 \%$ at $800 \mathrm{~nm}$ (see Table S3 in Supplementary Material). With few exceptions (at 200, 250, and $300 \mathrm{~nm}$ ), the transmittance values were lower in HT film. In the UV-light domain (200-350 nm), transmittance ranged from 0.01 to $11.13 \%$ for UNT films and from 0.17 to $7.01 \%$ for HT ones. Negligible transmittance values were noticed at $200 \mathrm{~nm}, 250 \mathrm{~nm}$, and $300 \mathrm{~nm}$ for both UNT and HT films. A possible explanation for this may be the high content of aromatic amino acids in the protein-based structure that can absorb UV radiation [31]. In the VIS-light domain (400-800 nm), transmittance ranged from 10.10 to $70.65 \%$ in UNT films and from 3.72 to $71.98 \%$ in HT ones. The above results indicate excellent barrier properties in the UV region for both UNT and HT films and better barrier properties in the VIS region for the HT film.

The addition of tarragon essential oil did not significantly influence the transmittance of film at wavelengths of $200 \mathrm{~nm}\left(p>0.05^{\mathrm{NS}}\right.$; contribution of $\left.10.3 \%\right)$ and $250 \mathrm{~nm}\left(p>0.05^{\mathrm{NS}}\right.$; contribution of $\left.1.5 \%\right)$; instead, it significantly influenced it at $300 \mathrm{~nm}(p<0.01 * *$; contribution of $12.4 \%), 350 \mathrm{~nm}(p<0.01 * *$; contribution of $25.5 \%), 400 \mathrm{~nm}\left(p<0.001^{* * *}\right.$; contribution of $\left.37.7 \%\right), 450 \mathrm{~nm}(p<0.001 * * ;$; contribution of $39.9 \%), 500 \mathrm{~nm}\left(p<0.001^{* * *}\right.$; contribution of $\left.36.5 \%\right), 550 \mathrm{~nm}\left(p<0.001^{* * *}\right.$; contribution of $\left.36.8 \%\right)$, $600 \mathrm{~nm}\left(p<0.001^{* * *}\right.$; contribution of $\left.35.5 \%\right), 650 \mathrm{~nm}\left(p<0.001^{* * *}\right.$; contribution of $\left.35.1 \%\right), 700 \mathrm{~nm}(p<$ $0.001^{* * *}$; contribution of $\left.35.1 \%\right), 750 \mathrm{~nm}\left(p<0.001^{* * *}\right.$; contribution of $\left.34.8 \%\right)$, and $800 \mathrm{~nm}(p<0.001$ ***; contribution of $34.6 \%$ ). In the case of UNT film, the transmittance showed an irregular behavior with the addition of tarragon essential oil, displaying an increasing-decreasing-increasing shape. Formulation C showed transmittance values between $0.24 \%$ (at $200 \mathrm{~nm}$ ) and $45.20 \%$ (at $800 \mathrm{~nm}$ and formulation F2.5 between $0.02 \%$ (at $200 \mathrm{~nm}$ ) and $49.80 \%$ (at $800 \mathrm{~nm}$ ). In the case of HT film, the transmittance value decreased with the addition of tarragon essential oil, thus enhancing its light-barrier properties. Formulation F2.5 had the lowest transmittance values at all measured wavelengths, ranging from $0.30 \%$ (at $200 \mathrm{~nm}$ ) to $7.22 \%$ (at $800 \mathrm{~nm}$ ), and formulation C the highest ones, ranging from $0.42 \%$ (at $200 \mathrm{~nm}$ ) to $71.98 \%$ (at $800 \mathrm{~nm}$ ).

Transparency value was significantly higher $\left(p<0.001^{* * *}\right)$ in the HT film, the contribution of heat-treatment factor being $26.3 \%$ (see Table S2 in Supplementary Material). Yet, the significant contribution $\left(p<0.001^{* * *}\right)$ of the addition of tarragon essential oil to the transparency of film was higher, of $34.7 \%$; an opposite behavior to light transmittance was noticed both in the UNT (irregular) and HT film (ascendant). In UNT films, formulation C had a transparency value of $1.3(\mathrm{~A} 600 / \mathrm{mm})$ and formulation F2.5 of 0.8 (A600/mm). In HT films, formulation C had a transparency value of 0.5 (A600/mm) while formulation F2.5 of 2.9 (A600/mm). As transmittance values were below $90 \%$ in all formulations, both UNT and HT films can be considered semi-transparent. 


\begin{tabular}{|r|r|r|r|r|r|r|}
\hline & \\
\hline
\end{tabular}

(a)

Figure 8. Cont. 


\begin{tabular}{|r|r|c|c|c|c|c|}
\hline & \multicolumn{7}{|c|}{ Heat-treated films } & & & \\
\hline
\end{tabular}

(b)

Figure 8. Light transmittance and transparency of edible films. (a) Untreated, (b) heat-treated. C-control film; F0.5-film with $0.5 \%$ tarragon essential oil; F1-film with $1 \%$ tarragon essential oil; F1.5-film with $1.5 \%$ tarragon essential oil; F2-film with $2 \%$ tarragon essential oil; F2.5-film with $2.5 \%$ tarragon essential oil. Values are expressed as mean \pm standard deviation of three replicates for light transmittance and transparency.

\subsubsection{Puncture Resistance (PR) and Puncture Deformation (PD)}

PR evaluates the film strength to penetration, while PD, the film elasticity under stress $[37,38]$. Figure 9a,b shows the values for PR and PD in UNT and HT films. The PR was significantly affected $\left(p<0.001{ }^{* * *}\right.$; contribution of $19.0 \%$ ) by heat treatment of the film-forming solution (see Table S4 in Supplementary Material). The value of PR was higher in HT film, thus showing better resistance to penetration compared to UNT film. The addition of tarragon essential oil also significantly affected $\left(p<0.001^{* * *}\right)$ the PR of the film, the contribution of this factor being higher, of $48.6 \%$. In UNT films, PR ranged from 0.4 to $6.2 \mathrm{~N} / \mathrm{mm}$ manifesting irregular behavior. In HT films, it ranged from 2.1 and $5.6 \mathrm{~N} / \mathrm{mm}$, decreasing with the addition of tarragon essential oil up to formulation $\mathrm{F} 2$, then increasing in F2.5. Comparable levels of PR, ranging between 3.83 and $4.44 \mathrm{~N} / \mathrm{mm}$, were found in edible films prepared from mucilage powders of three cultivars of Opuntia ficus-indica (0.5\%), pectin $(0.7 \%)$, glycerol $(1 \%)$, and $(97.8 \%)$ water [39]. Higher levels of PR were reported by Jiang et al. (2010) in edible film 
prepared with $10 \%$ WPI, $4 \%$ glycerol, and $86 \%$ water (of $25.0 \mathrm{~N} / \mathrm{mm}$ ), and by Machado Azevedo et al. (2017) in edible film prepared with $60 \%$ corn starch/WPI blend $(1: 1, w / w), 24 \%$ glycerol, and $16 \%$ water (of $11.5 \mathrm{~N} / \mathrm{mm}$ ) [34,40]. These findings would seem to show that PR value is related to the water content of the film. The low values of resistance to puncture force in our films are probably due to their high moisture content.

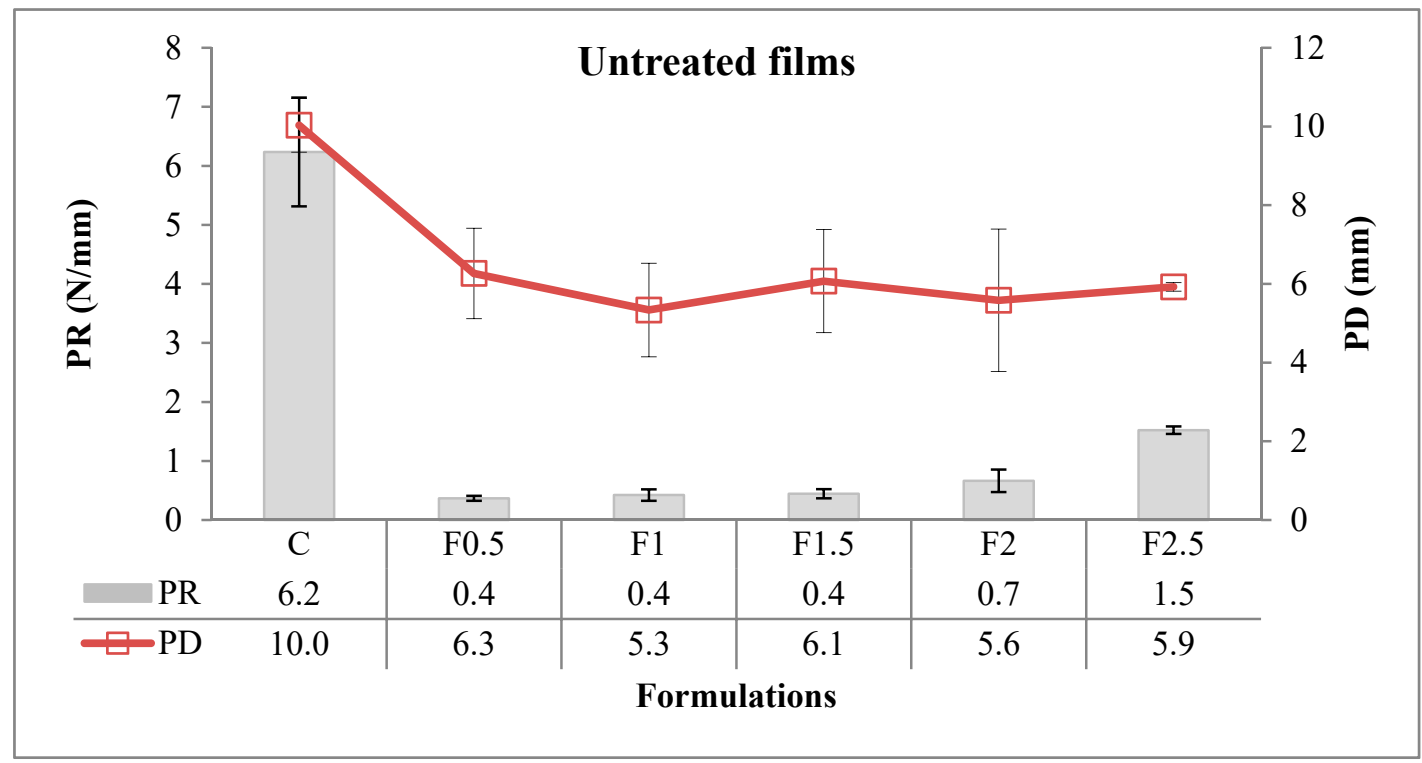

(a)

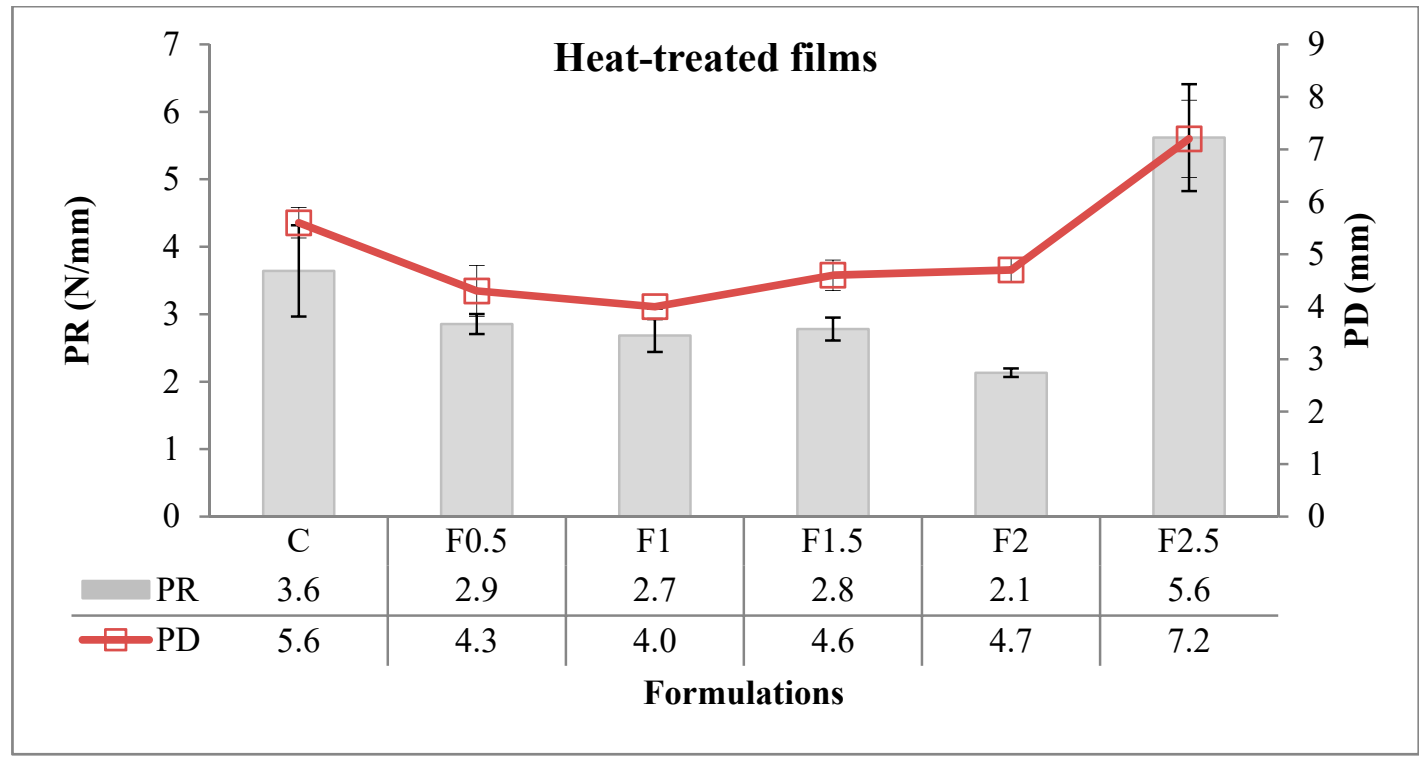

(b)

Figure 9. Puncture resistance (PR) and puncture deformation (PD) of edible films. (a) Untreated, (b) heat-treated. C-control film; F0.5-film with $0.5 \%$ tarragon essential oil; F1-film with 1\% tarragon essential oil; F1.5-film with 1.5\% tarragon essential oil; F2-film with 2\% tarragon essential oil; F2.5-film with $2.5 \%$ tarragon essential oil. Values are expressed as mean \pm standard deviation of four replicates for PR and PD.

The PD was significantly affected $\left(p<0.001^{* * *}\right.$; contribution of $\left.18.8 \%\right)$ by heat treatment of the film-forming solution (see Table S4 in Supplementary Material). In contrast to PR, the value of PD was lower in HT film, thus showing lower elasticity than UNT film. The contribution of tarragon 
essential oil addition was also significant $\left(p<0.001^{* * *}\right)$ but higher as a share $(38.1 \%)$. In UNT films, PD varied from 5.3 to $10.0 \mathrm{~mm}$, having chaotic behavior. In HT films, it varied from 4.0 to $7.2 \mathrm{~mm}$, initially decreasing with the addition of tarragon essential oil up to formulation F1, then increasing up to F2.5. This is probably due to the plasticizing effect of tarragon essential oil at a concentration above $1 \%$. Jiang et al. (2010) found a higher level of PD in edible film prepared with $10 \%$ WPI, of $12.0 \mathrm{~mm}$ [34]. Surprisingly, Machado Azevedo et al. (2017) reported a lower level of PD in edible film prepared with corn starch/WPI blend, of $1.86 \mathrm{~mm}$ [40].

\section{Conclusions}

The essential oil of tarragon has shown to possess both antioxidant and antibacterial activities. The WPI-based edible film was affected by heat treatment of the filmogenic solution. HT film showed improved physical and mechanical properties, being more transparent, less soluble in water, more light protective in the range of $350-800 \mathrm{~nm}$, and more resistant to mechanical penetration. Therefore, it is more suitable for certain end-use applications. With the addition of tarragon essential oil, the HT film became more red-yellowish, more transparent, more protective against VIS light, more resistant to puncture, and more elastic. Further research is needed to determine the effectiveness of the edible film with $2.5 \%$ tarragon essential oil in extending the shelf-life of food.

Supplementary Materials: The following are available online at http://www.mdpi.com/2073-4360/12/8/1748/s1, Table S1: Effects of heat treatment of the film-forming solution, the addition of tarragon essential oil, and their first-degree interaction on thickness, moisture content, swelling degree, solubility in water, and WVP of edible films. Table S2: Effects of heat treatment of the film-forming solution, the addition of tarragon essential oil, and their first-degree interaction on color and transparency of edible films. Table S3: Effects of heat treatment of the film-forming solution, the addition of tarragon essential oil, and their first-degree interaction on light transmittance of edible films. Table S4: Effects of heat treatment of the film-forming solution, the addition of tarragon essential oil, and their first-degree interaction on puncture resistance and puncture deformation of edible films.

Author Contributions: Conceptualization, C.A.S. and D.C.V.; methodology, C.A.S. and D.C.V.; formal analysis, M.-I.S., M.F., S.A.S., M.A.R., and V.M.; writing—original draft preparation, M.-I.S.; writing—review and editing, C.A.S.; visualization, O.L.P. and D.C.V.; supervision, C.A.S. and D.C.V.; project administration, C.A.S. and D.C.V.; funding acquisition, D.C.V. All authors have read and agreed to the published version of the manuscript.

Funding: This research was funded by a grant from the Ministry of Research and Innovation, as follows: CNCS-UEFISCDI, project number PN-III-P1-1.2-PCCDI-2017-0056, 2 PCCDI within PNCDI III; and the publication was supported by funds from the National Research Development Projects to finance excellence (PFE)-37/2018-2020 granted by the Romanian Ministry of Research and Innovation.

Acknowledgments: We are grateful for the administrative and financial support received from the University of Agricultural Sciences and Veterinary Medicine Cluj-Napoca, Romania.

Conflicts of Interest: The authors declare no conflict of interest. The funders had no role in the design of the study; in the collection, analyses, or interpretation of data; in the writing of the manuscript, or in the decision to publish the results.

\section{References}

1. Socaciu, M.I.; Semeniuc, C.A.; Vodnar, D.C. Edible films and coatings for fresh fish packaging: Focus on quality changes and shelf-life extension. Coatings 2018, 8, 366. [CrossRef]

2. Sothornvit, R.; Krochta, J.M. Plasticizers in edible film and coatings. In Innovations in Food Packaging, 1st ed.; Han, J.H., Ed.; Elsevier-Academic Press: Amsterdam, The Netherlands, 2005; pp. 403-433.

3. Erginkaya, Z.; Kalkan, S.; Ünal, E. Use of antimicrobial edible films and coatings as packaging materials for food safety. In Food Processing: Strategies for Quality Assessment; Malik, A., Erginkaya, Z., Ahmad, S., Erten, H., Eds.; Springer: New York, USA, 2014; pp. 261-295.

4. Morar, M.I.; Fetea, F.; Rotar, A.M.; Nagy, M.; Semeniuc, C.A. Characterization of essential oils extracted from different aromatic plants by FTIR spectroscopy. Bull. UASVM Food Sci. Technol. 2017, 74, 37-38. [CrossRef]

5. Semeniuc, C.A.; Socaciu, M.I.; Socaci, S.A.; Mureşan, V.; Fogarasi, M.; Rotar, A.M. Chemometric comparison and classification of some essential oils extracted from plants belonging to Apiaceae and Lamiaceae families based on their chemical composition and biological activities. Molecules 2018, 23, 2261. [CrossRef] [PubMed] 
6. Kordali, S.; Kotan, R.; Mavi, A.; Cakir, A.; Ala, A.; Yildirim, A. Determination of the chemical composition and antioxidant activity of the essential oil of Artemisia dracunculus and of the antifungal and antibacterial activities of Turkish Artemisia absinthium, A. dracunculus, Artemisia santonicum, and Artemisia spicigera essential oils. J. Agric. Food Chem. 2005, 53, 9452-9458. [CrossRef] [PubMed]

7. Lopes-Lutz, D.; Alviano, D.S.; Alviano, C.S.; Kolodziejczyk, P.P. Screening of chemical composition, antimicrobial and antioxidant activities of Artemisia essential oils. Phytochemistry 2008, 69, 1732-1738. [CrossRef]

8. Sharafati Chaleshtori, R.; Rokni, N.; Razavilar, V.; Rafieian Kopaei, M. The evaluation of the antibacterial and antioxidant activity of tarragon (Artemisia dracunculus L.) essential oil and its chemical composition. Jundishapur J. Microbiol. 2013, 6, e7877. [CrossRef]

9. Behbahani, B.A.; Shahidi, F.; Yazdi, F.T.; Mortazavi, S.A.; Mohebbi, M. Antioxidant activity and antimicrobial effect of tarragon (Artemisia dracunculus) extract and chemical composition of its essential oil. J. Food Meas. Charact. 2017, 11, 847-863. [CrossRef]

10. Kıvanç, M.; Akgül, A. Antibacterial activities of essential oils from Turkish spices and citrus. Flavour Frag. J. 1986, 1, 175-179. [CrossRef]

11. Juteau, F.; Jerkovic, I.; Masotti, V.; Milos, M.; Mastelic, J.; Bessière, J.M.; Viano, J. Composition and antimicrobial activity of the essential oil of Artemisia absinthium from Croatia and France. Planta Med. 2003, 69, 158-161. [CrossRef]

12. Obolskiy, D.; Pischel, I.; Feistel, B.; Glotov, N.; Heinrich, M. Artemisia dracunculus L. (tarragon): A critical review of its traditional use, chemical composition, pharmacology, and safety. J. Agric. Food Chem. 2011, 59, 11367-11384. [CrossRef]

13. Aulin, C.; Lindström, T. Biopolymer films and coatings. In Biopolymers -New Materials for Sustainable Films and Coatings, 1st ed.; Plackett, D., Ed.; John Wiley \& Sons: Chichester, UK, 2011; pp. 257-276.

14. Chen, H.; Wang, J.; Cheng, Y.; Wang, C.; Liu, H.; Bian, H.; Pan, Y.; Sun, J.; Han, W. Application of protein-based films and coatings for food packaging: A review. Polymers 2019, 11, 2039. [CrossRef] [PubMed]

15. Shendurse, A.M.; Gopikrishna, G.; Patel, A.C.; Pandya, A.J. Milk protein based edible films and coatings-preparation, properties and food applications. J. Nutr. Health Food Eng. 2018, 8, 219-226. [CrossRef]

16. Sanjeev, A.; Khanal, S.N.; Marella, C. Whey and whey products. In Milk and Dairy Products in Human Nutrition: Production, Composition and Health; Park, Y.W., Haenlein, G.F.W., Eds.; John Wiley \& Sons: Chichester, UK, 2013; pp. 477-497.

17. Guo, M.; Wang, G. Whey protein polymerisation and its applications in environmentally safe adhesives. Int. J. Dairy Technol. 2016, 69, 481-488. [CrossRef]

18. Khwaldia, K.; Perez, C.; Banon, S.; Desobry, S.; Hardy, J. Milk proteins for edible films and coatings. Crit. Rev. Food Sci. Nutr. 2004, 44, 239-251. [CrossRef] [PubMed]

19. Kokoszka, S.; Debeaufort, F.; Lenart, A.; Voilley, A. Water vapour permeability, thermal and wetting properties of whey protein isolate based edible films. Int. Dairy J. 2010, 20, 53-60. [CrossRef]

20. Gurgel Adeodato Vieira, M.; Altenhofen da Silva, M.; Oliveira dos Santos, L.; Masumi Beppu, M. Natural-based plasticizers and biopolymer films: A review. Eur. Polym. J. 2011, 47, 254-263. [CrossRef]

21. Suppakul, P. Packaging, active, and intelligent: Polymer application. In Encyclopedia of Polymer Applications, 1st ed.; Mishra, M., Ed.; CRC Press: Boca Raton, USA, 2019; pp. 1958-1989.

22. Ullsten, N.H.; Gällstedt, M.; Hedenqvist, M.S. Plasticizers for protein-based materials. In Viscoelastic and Viscoplastic Materials; El-Amin, M., Ed.; IntechOpen: London, UK, 2016; pp. 81-101.

23. The Pherobase: Database of Pheromones and Semiochemicals. Available online: www.pherobase.com (accessed on 29 April 2020).

24. Flavornet and Human Odor Space. Available online: www.flavornet.org (accessed on 29 April 2020).

25. McFarland, J. Nephelometer: An instrument for estimating the number of bacteria in suspensions used for calculating the opsonic index and for vaccines. JAMA 1907, XLIX, 1176-1178. [CrossRef]

26. Semeniuc, C.A.; Pop, C.R.; Rotar, A.M. Antibacterial activity and interactions of plant essential oil combinations against Gram-positive and Gram-negative bacteria. J. Food Drug. Anal. 2017, 25, 403-408. [CrossRef] 
27. Badr, K.R.; Ahmed, Z.S.; ElGamal, M.S. Evaluation of the antimicrobial action of whey protein edible films incorporated with cinnamon, cumin and thyme against spoilage flora of fresh beef. Int. J. Agric. Res. 2014, 9, 242-250. [CrossRef]

28. Wang, J.; Shang, J.; Ren, F.; Leng, X. Study of the physical properties of whey protein: Sericin protein-blended edible films. Eur. Food Res. Technol. 2010, 231, 109-116. [CrossRef]

29. Ghasemlou, M.; Aliheidari, N.; Fahmi, R.; Shojaee-Aliabad, S.; Keshavarz, B.; Cran, M.J.; Khaksar, R. Physical, mechanical and barrier properties of corn starch films incorporated with plant essential oils. Carbohydr. Polym. 2013, 98, 1117-1126. [CrossRef] [PubMed]

30. Hernandez, R.J. Food packaging materials, barrier properties, and selection. In Handbook of Food Engineering Practice; Valentas, K.J., Rotstein, E., Singh, R.P., Eds.; CRC Press: Boca Raton, USA, 1997; pp. 307-360.

31. Ramos, Ó.L.; Reinas, I.; Silva, S.I.; Fernandes, J.C.; Cerqueira, M.A.; Pereira, R.N.; Vicente, A.A.; Poças, M.F.; Pintado, M.E.; Malcata, F.X. Effect of whey protein purity and glycerol content upon physical properties of edible films manufactured therefrom. Food Hydrocoll. 2013, 30, 110-122. [CrossRef]

32. Mitrea, L.; Călinoiu, L.F.; Martău, G.A.; Szabo, K.; Teleky, B.E.; Mureșan, V.; Rusu, A.V.; Socol, C.T.; Vodnar, D.C. Poly(vinyl alcohol)-based biofilms plasticized with polyols and colored with pigments extracted from tomato by-products. Polymers 2020, 12, 532. [CrossRef] [PubMed]

33. Šuput, D.; Lazić, V.; Popović, S.; Hromiš, N.; Bulut, S. Biopolymer films synthesis and characterization. J. Process. Energy Agric. 2017, 21, 9-12. [CrossRef]

34. Jiang, Y.; Li, Y.; Chai, Z.; Leng, X. Study of the physical properties of whey protein isolate and gelatin composite films. J. Agric. Food Chem. 2010, 58, 5100-5108. [CrossRef] [PubMed]

35. Ramos, Ó.L.; Silva, S.I.; Soares, J.C.; Fernandes, J.C.; Fátima Poças, M.; Pintado, M.E.; Malcata, F.X. Features and performance of edible films, obtained from whey protein isolate formulated with antimicrobial compounds. Food Res. Int. 2012, 45, 351-361. [CrossRef]

36. Pérez-Gago, M.B.; Nadaud, P.; Krochta, J.M. Water vapor permeability, solubility, and tensile properties of heat-denatured versus native whey protein films. J. Food Sci. 1999, 64, 1034-1037. [CrossRef]

37. Perez, O.E.; Carrera-Sanchez, C.; Rodriguez-Patino, J.M.; Pilosof, A.M.R. Behavior of hydroxypropylmethylcelluloses of different molecular structure and water affinity at the air-water interface. In Water Properties of Food, Pharmaceutical, and Biological Materials, 1st ed.; del Pilar Buera, M., Welti-Chanes, J., Lillford, P.J., Corti, H.R., Eds.; CRC Press: Boca Raton, USA, 2006; pp. 445-454.

38. Athavale, S.P. Hand Book of Printing, Packaging and Lamination: Packaging Technology, 1st ed.; Notion Press: Chennai, India, 2018; pp. 319-388.

39. González Sandoval, D.C.; Luna Sosa, B.; Martínez-Ávila, G.C.G.; Rodríguez Fuentes, H.; Avendaño Abarca, V.H.; Rojas, R. Formulation and characterization of edible films based on organic mucilage from Mexican Opuntia ficus-indica. Coatings 2019, 9, 506. [CrossRef]

40. Machado Azevedo, V.; Vilela Borges, S.; Marconcini, J.M.; Yoshida, M.I.; Sena Neto, A.R.; Coelho Pereira, T.; Ferreira Gonçalves Pereira, C. Effect of replacement of corn starch by whey protein isolate in biodegradable film blends obtained by extrusion. Carbohydr. Polym. 2017, 157, 971-980. [CrossRef]

(C) 2020 by the authors. Licensee MDPI, Basel, Switzerland. This article is an open access article distributed under the terms and conditions of the Creative Commons Attribution (CC BY) license (http://creativecommons.org/licenses/by/4.0/). 